\title{
STT\#47020 QA:NA 2/23/06 Use of Coupled Multi-Electrode Arrays to Advance the Understanding of Selected Corrosion Phenomena
}

\author{
N. D. Budiansky, F. Bocher, H. Cong, M. F. Hurley, and J. R. Scully \\ Center for Electrochemical Science and Engineering \\ Department of Materials Science and Engineering \\ University of Virginia \\ 116 Engineer's Way \\ Charlottesville, VA, USA 22904
}

\begin{abstract}
The use of multi-coupled electrode arrays in various corrosion applications is discussed with the main goal of advancing the understanding of various corrosion phenomena. Both close packed and far spaced electrode configurations are discussed. Far spaced electrode arrays are optimized for high throughput experiments capable of elucidating the effects of various variables on corrosion properties. For instance the effects of a statistical distribution of flaws on corrosion properties can be examined. Close packed arrays enable unprecedented spatial and temporal information on the behavior of local anodes and cathodes. Interactions between corrosion sites can trigger or inhibit corrosion phenomena and affect corrosion damage evolution.
\end{abstract}

\section{INTRODUCTION}

Many forms of corrosion are highly localized such that the local electrochemical processes differ significantly from the global processes averaged over entire electrodes. A few techniques exist to probe local processes, which include: scanning or localized electrical impedance spectroscopy, scanning vibrating probe, ${ }^{1}$ multi-electrode arrays, ${ }^{2-21}$ and scanning electrochemical microscopy. ${ }^{22,}{ }^{23}$ One of the most powerful methods is coupled multi-electrode arrays (or assemblies) (MEAs). ${ }^{2,3}$ MEAs are arrays of electrically isolated electrodes. These electrode elements are coupled together, through in-line zero resistance ammeters (ZRA), to form a galvanically coupled electrode surface. ${ }^{2,3}$ The coupled electrodes are designed to closely simulate a planar electrode surface but allow current behavior of each electrode to be monitored. Typically, MEAs are composed of nominally identical electrodes, to simulate larger planar electrodes, or a combination of different electrode materials, to mimic the periodicity and type of compositional and structural non-uniformities in complex technological alloys. For instance, $\mathrm{Cu}$ electrodes can be placed among $\mathrm{Al}$ to simulate $\mathrm{Al}-\mathrm{Cu}$ alloys. The key advantage over other methods is MEAs allow temporal and spatial measurements of electrochemical processes simultaneously. This advantage allows the measurement of real-time processes that take place on electrode surfaces. 
Far spaced electrode configurations allow high throughput testing of essentially independent electrodes to the identical environment because the distance between electrodes is much larger than the dimensions of single electrodes. Using multi-electrode systems, for high throughput testing, eliminates variations in test environment and conditions by running all the samples simultaneously, during the same test, under the same exact test conditions. ${ }^{24}$ The distance between these electrodes should be large enough that the processes taking place on each electrode during anodic or cathodic polarization will not affect neighboring electrodes through coupling via chemical or potential fields. This is accomplished by maintaining separation distances greater than characteristic transport lengths increasing the ohmic resistance so that galvanic coupling is suppressed and by keeping experimental times short.

In contrast, close spaced electrodes are placed in a configuration that allows neighboring electrodes to be affected by adjacent electrochemical processes that are coupled chemically and electrochemically, such that behavior is indistinguishable from one continuous electrode. Another advantage of MEAs is the ability to induce electrochemical processes on specific regions of the MEA, while monitoring their effect on the remainder of the electrode elements. These control capabilities enable the investigation of specific corrosion mechanisms (i.e., pitting corrosion, intergranular corrosion, crevice corrosion, underpaint corrosion, galvanic corrosion and global depassivation). A third advantage is the ability to separately address individual electrodes and then interrogate the properties of specific electrodes by switching a selected electrode out of the array in order to perform detailed electrochemical measurements. For example, persistent anodes or cathodes can form under open circuit conditions. Under these conditions, where no potential is applied, the spatial proximity of localized corrosion events or separation of anodes and cathodes can be monitored under real time conditions. Moreover, the specific properties of anodes and cathodes may then be examined. It is useful to understand criteria for coupling between individual electrode elements. MEAs enable the separation of local anodes and cathodes by measuring the net current from each electrode element through inline ZRAs. Recall that one desires to match the "size" MEA electrodes to the size of local anodes and cathodes so that separate behavior of anodes and cathodes can be investigated. However, even on small wire electrodes local anodic and cathodic reactions occur even when the wire size is reduced to the size of local anodes and cathodes. For instance, $15-20 \%$ of the cathodic reaction occurs within anodic pits on aluminum alloys. ${ }^{25,26}$ As in all electrochemical systems operating at some mixed potential (i.e., the corrosion potential in a corroding situation) the sum of the anodic currents is equal to the sum of the cathodic currents.

$$
\sum I_{\text {Anodic }}=\sum I_{\text {Cathodic }}
$$

If Anodically Polarized:

$$
\sum I_{\text {Anodic }}^{\text {Applied }}=\sum I_{\text {Cathodic }}^{\text {Applied }}+I_{\text {Cathodic }}^{\text {CE Potentiostat }}
$$

Where: $\sum I_{\text {Anodic }}^{\text {Net }{ }_{\text {Anode }}}+\sum I_{\text {Anodic }}^{\text {Net_Cathode }}=\sum I_{\text {Anodic }}^{\text {Applied }}$ and $\sum I_{\text {Cathodic }}^{\text {Net_Anode }}+\sum I_{\text {Cathodic }}^{\text {Net_Cathode }}=\sum I_{\text {Cathodic }}^{\text {Applied }}$

On each electrode element in the MEA the measured current, through a ZRA, is either net anodic or net cathodic. However, on any size electrode elements anodic and cathodic reactions are still possible.

$$
\sum I_{\text {Anodic }}^{\text {Net_Anode }}+\sum I_{\text {Anodic }}^{\text {Net_Cathode }}=\sum I_{\text {Cathodic }}^{\text {Net_Anode }}+\sum I_{\text {Cathodic }}^{\text {Net_Cathode }}+I_{\text {Cathodic }}^{\text {CE_Potentiosatc }}
$$


The current measured on each electrode element is the net current from local sites. Rearranging the equations gives the actual measured currents in the case of anodic polarization the following equation applies.

$$
\left(\sum I_{\text {Anodic }}^{\text {Net }}{ }_{\text {Anode }}-\sum I_{\text {Cathodic }}^{\text {Net_Anode }}\right)=\left(\sum I_{\text {Cathodic }}^{\text {Net_Cathode }}-\sum I_{\text {Anodic }}^{\text {Net_Cathode }}\right)+I_{\text {Cathodic }}^{\text {CE_Potiost }}
$$

The quantity in parenthesis is what is actually measured. Therefore, it should be recognized that only the net anodic and net cathodic currents are measured on each electrode in an MEA.

\section{Coupling of Electrodes Through Potential Fields}

Electrical coupling between electrodes is governed by ionic resistance, in the electrolyte, and electrical resistance in the material between wires. The electrical resistance, between wires, is negligible when using ZRAs. The ionic resistance between electrodes is dependent on electrode spacing and ionic conductivity. During the growth of large pits, according to the acid pitting mechanism, metal ion hydrolysis takes place within the pit, $\mathrm{Cl}^{-}$and $\mathrm{H}^{+}$ions accumulate within and around the pit, and currents flow from the pit. ${ }^{27}$ As currents flow through the solution, a potential gradient is formed near a pit due to solution resistance dictated by Ohm's law. Under potentiodynamic or potentiostatic conditions the applied potential and true interfacial potential may not be equal. The adjacent electrodes could be shielded from achieving high interfacial potentials during anodic polarization. If there is a large ohmic voltage $\left(\mathrm{V}_{\text {ohmic }}\right)$ :

$$
E_{\text {Applied/Measured }}=E_{\text {Interface }}+V_{\text {ohmic }}
$$

Where:

$\mathrm{E}_{\text {Applied/Measured }}=$ The remotely applied and measure potential

$\mathrm{E}_{\text {Interface }}=$ Interfacial potential

$\mathrm{V}_{\text {ohmic }}=$ Ohmic potential supplied from local electrochemical processes

A large $\mathrm{V}_{\text {ohmic }}$ can lower the interfacial potential. As the distance from the active pits increases, the ohmic potential $\left(\mathrm{V}_{\text {ohmic }}\right)$ decreases. Therefore, any remotely measured potential is closer to the true interfacial potential. Lunt, et al. used Newman's solution ${ }^{28}$, for a disk in an insulator, to calculate the ohmic potential drop vs. distance from a disk in an insulated flat surface. ${ }^{4} 6$ This model is a good approximation for a pit or any other active sites on a passive electrode surface during net polarization. Using the equations for Newman's solution and some experimental values the ohmic potential drop can be estimated by:

$$
\begin{gathered}
\frac{\Phi}{\Phi_{0}}=1-\left(\frac{2}{\pi}\right) \cdot \tan ^{-1}(\xi) \\
I=4 \mathrm{~K} \cdot \mathbf{r}_{0} \cdot \Phi_{0}
\end{gathered}
$$




$$
r=r_{0} \cdot \sqrt{\left(1+\xi^{2}\right) \cdot(1-\eta)^{2}}
$$

Where:

$\Phi=$ Ohmic potential (V)

$\Phi_{0}=$ Maximum ohmic potential (V)

$\xi=$ Distance from center of disk, in elliptical coordinates $(\mathrm{cm})$

$\eta=$ Second elliptical coordinate (in this case $=0$ )

$r=$ Normalized distance from center of disk $(\mathrm{cm})$

$\mathrm{I}=$ Total current from disk (A)

$\mathrm{K}=$ Solution conductivity $\left(\Omega^{-1}-\mathrm{cm}^{-1}\right)$

$r_{0}=$ Radius of electrode $(\mathrm{cm})$

Newman's solution predicts that the ohmic potential will decrease rapidly from the current source, as shown by Figure 1a. 6 As the solution conductivity changes, not only does the potential field change lateral dimensions but the maximum ohmic potential changes as well. The ohmic potential drop causes a decrease in the interfacial potential, which can affect the driving force for interfacial reactions. For example, a potential distribution is expected to form adjacent to the anodic site for a current density of $0.1 \mathrm{~A} / \mathrm{cm}^{2}$, simulating a persistent anode, that varies with solution conductivity $(\mathrm{K})$, as shown in Figure 1a. At a distance of three electrode diameters (approximately $0.05 \mathrm{~cm}$ ) from the anodic site the ohmic potential is predicted to be approximately $10 \%$ of the maximum ohmic potential.

\section{Coupling of Electrodes Through Chemical Interactions}

Chemical coupling is governed by overlapping concentration fields from adjacent electrodes. This may trigger behavior on adjacent electrodes not seen on isolated electrodes or overlooked on large electrodes where average behavior is assumed. The local solutions in and near active pits are different than the bulk due to the electrochemical and chemical reactions associated with the acid-halide pitting model. ${ }^{27}$ Aggressive ion enhancement near active pits causes a concentration gradient to form laterally. Measurements of $\mathrm{pH}$ gradients around pits have showed a $\mathrm{pH}$ gradient change of six $\mathrm{pH}$ units that extended several pit diameters way from the pit cavity. ${ }^{29}$ Other sources of chemical species include $\mathrm{OH}^{-}$ production at strong local cathodes. Lunt, et al. used equations by Carslaw and Jaeger to calculate the normalized concentration profile lateral to active pits. ${ }^{4}$ According to Carslaw and Jaeger, the normalized concentration profile is given by: ${ }^{30}$

$$
\frac{C_{r}}{C_{p i t}}=\frac{a}{r} * \operatorname{erfc}\left(\frac{r-a}{2 \sqrt{D t}}\right)
$$

Where:

$\mathrm{C}_{\mathrm{r}}=$ concentration at a distance $\mathrm{r}$ from the pit mouth (Moles/l)

$\mathrm{C}_{\text {pit }}=$ concentration inside the pit (Moles/l)

$\mathrm{a}=$ radius of the pit $(\mathrm{cm})$

$r=$ radial distance away from the pit mouth $(\mathrm{cm})$

erfc $=$ complementary error function

$\mathrm{D}=$ diffusion coefficient of the diffusion ion $\left(\mathrm{cm}^{2} / \mathrm{s}\right)$

$\mathrm{t}=$ time (seconds) 
Equation (9) is the Laplace Solution for a sphere in an insulating surface under stagnant conditions. More sophisticated solutions exist for the case of stirring with diffusional boundary layer. ${ }^{31}$ However, the results are a fairly good prediction for a pit with a fixed chemical concentration in a passive surface behaving as an inert surface. Consider the case where pits grow across the entire electrode surface of a single $150 \mu \mathrm{m}$ wire in an MEA. The predicted concentration field for $\mathrm{H}^{+}$ions with a diffusivity of $1 \times 10^{-5} \mathrm{~cm} / \mathrm{s}$ at different times, is shown in Figure $1 \mathrm{~b}$. The calculated $\mathrm{H}^{+}$ion concentration drops off rapidly, away from the pit cavity, and has a concentration of less than $50 \%$ of the concentration found in the pit cavity at one pit diameter away, as shown in Figure 1b. At a distance of four or five pit diameters, the concentration is determined to be less than $10 \%$ of the pit cavity concentration. The concentration field reaches relative steady state, after approximately 1200 seconds, as shown in Figure 1b. Changes in the local solution concentration can affect the electrochemical processes that occur within the range of altered solution.

As described above, far spaced MEA configurations are designed to ensure chemical and electrochemical isolation from neighboring electrodes. Thus, each electrode can be assumed to act independently of one another. For example, if a far-spaced MEA, constructed from $150 \mu \mathrm{m}$ wires with a inter-electrode spacing of $3 \mathrm{~mm}$, is used in a pitting experiment and a single electrode undergoes pitting across its entire surface area, then $\mathrm{C}_{\mathrm{r}} / \mathrm{C}_{\mathrm{pit}}$ will be equal to 0.003 after 1800 seconds at the edge of the nearest neighboring electrode, $3 \mathrm{~mm}$ away. At $3 \mathrm{~mm}$ away from the pit cavity it is possible to have a $\mathrm{pH}$ of 4.5 assuming that the test solution is initially near neutral and a $\mathrm{pH}$ of 2 exists within the pit cavity. It also assumed that there are no other transport mechanisms that will disrupt ion diffusion. Simple calculations using $l=(D t)^{-1 / 2}$, where 1 is the length and $D$ is the diffusion constant, in one dimension, are also useful. If time experiment $<\mathrm{t}=\mathrm{l}^{2} / \mathrm{D}$, then chemical interactions are unlikely in this one dimensional case. Thus, short experiments and large distances between electrodes ensure chemical isolation of electrodes in far spaced MEAs. The text that follows provides background on each application discussed here.

\section{Interplay between Water Chemistry and Electrochemical Properties of Copper}

Copper tubes account for more than $80 \%$ of all tubes in potable water distribution systems in the U.S.A. Rates of copper pinhole leaks have reached crisis levels, because "pinhole" pitting corrosion accounts for more than $60 \%$ of the failures that occur. ${ }^{32}$ Furthermore, this phenomena is on the increase. Pitting corrosion is an insidious form of corrosion that can lead to premature failure of copper tube. During pitting corrosion the anode and cathode areas on the pipe surface are separated to a high degree. The ratio of cathode/anode areas is high, and anodes are persistent. There also exists a necessary but not sufficient electrochemical condition for pitting susceptibility. That is, if the open circuit potential rises above a critical pitting potential value, which depends on the materials and environment, pitting corrosion occurs. This phenomenon occurs under specific water chemistries ${ }^{33-35}$ or material conditions. ${ }^{32}$ Literature reviews have compiled lists of selected waters that cause cold water pitting, but specifics governing initiation and propagation, as a function of water chemistry variables are unclear. ${ }^{33}$ Moreover, such pitting is hard to reproduce in laboratory experiments even when water chemistries are replicated. In the context of this paper, the focus is to examine the development of persistent local anodes as a function of water chemistry. MEAs provide an opportunity to study this phenomenon. 


\section{Corrosion Spreading in Concrete}

Reinforced concrete structures are susceptible to damage from chloride and/or carbonation induced corrosion of the embedded reinforcement. ${ }^{36}$ Corrosion product accumulation at the concrete/rebar interface eventually results in a stress state that is sufficient to cause cracking of the surrounding concrete. $^{36}$ Concrete cracking leads to mechanical degradation of the structure and provides a more direct channel for aggressive ion transport to the rebar surface.

The lifetime of a concrete structure can be considered as the sum of the time required to initiate corrosion and the duration of the corrosion propagation period sufficient to cause concrete cracking. ${ }^{37}$ To extend the lifetime of reinforced concrete structures, new higher corrosion resistant rebar alloys are being considered as a replacement for conventional carbon steel. ${ }^{38}$ For example, various stainless steel rebar alloys and stainless steel clad over carbon steel are under consideration. The potential extension of concrete structure lifetimes afforded by new candidate rebar alloys depends not only on their corrosion initiation but also on their corrosion propagation characteristics. It is theoretically possible that a candidate rebar that is better from the initiation perspective is worse from the propagation perspective. To justify the higher cost of stainless steel rebar alloys, it is necessary to perform relevant laboratory and/or field-testing to characterize the corrosion behavior (initiation and propagation) prior to implementation. To qualify new rebar materials, the chloride threshold for corrosion initiation, radial and lateral propagation rates, and Pilling-Bedworth ratios (ratio of the relative volume of an oxide and its parent metal) must be determined. These factors play a significant role in determining how corrosion of specific rebar alloys will affect concrete structure lifetimes.

The corrosion propagation behavior as well as the morphology of attack directly affects the propensity for concrete cracking. In one study on carbon steel bars, it was found that the critical depth of attack required to crack concrete, $\mathrm{X}_{\text {crit, }}$ was a function of the specimen radius, $\mathrm{r}$, concrete cover thickness, $\mathrm{C}$, and the length of anodic region along the axis of the bar, $L^{39}$ Specifically, $X_{\text {crit }}$ is proportional to the first power of $[\mathrm{C} / 2 \mathrm{r}]$ and to a higher power of $[\mathrm{C} / \mathrm{L}+1]$. Hence, as the length of anodic region of corrosion propagation, $\mathrm{L}$, increases, $\mathrm{X}_{\text {crit }}$ decreases. Given such a dependency on $\mathrm{L}, \mathrm{X}_{\text {crit }}$ would be expected to be very large if a material can be selected such that $\mathrm{L}$ is kept at minimum. The implication is that use of a stainless steel or material that limits L by forming high aspect ratio pits with limited lateral spreading offers the opportunity to extend the life of concrete structures in addition to any benefit attributed to increased chloride thresholds. Hence, the lateral spread of corrosion is important to the ultimate performance of new rebar candidates. MEAs provide the opportunity to study this phenomenon by providing spatial and temporal measurements of corrosion initiation and propagation.

\section{Crevice Corrosion}

Traditionally, the study of crevice corrosion has been conducted using two methods. The first involves a qualitative method consisting of multi-crevice former that is applied on the surface of the sample using a set torque. ${ }^{40}$ Specimens are immersed in a standardized solution over a long period of time. Alloys susceptible to crevice corrosion are compared by determining the number of sites that initiated under a multiple crevice former. Very little electrochemical information is provided although open circuit potential may be monitored if an electrical connection is provided and crevice current may be monitored if the specimen is polarized. A second method, investigating the electrochemical behavior and providing quantitative results, uses either a sample under a crevice former or in a model crevice solution. ${ }^{41} \mathrm{~A}$ potentiodynamic scan is performed giving E- $\log (\mathrm{i})$ behavior and the critical initiation potential and 
repassivation potential can be determined. Even though these techniques offer a wide range of important information, many questions about crevice corrosion remain unresolved. The multi-crevice test provides the depth, morphology, and area of the attack as well as giving the probability of crevice corrosion attack. Unfortunately, the current density is not homogeneous over the crevice area, and the exact crevice area is unknown. Therefore, the exact crevice corrosion initiation position, growth of breakdown sites and their propagation rates are uncertain. Techniques for spatially and temporarily resolved crevice corrosion are limited. Using an optical transparent crevice former (glass) and a confocal laser scanning microscope or other non-contact profilometry equipment, the spatial distribution of crevice corrosion has been addressed. ${ }^{42}$ Of course, scanning probe methods discussed above are thwarted by the physical presence of the crevice former.

Using an electrochemically coupled, yet separately addressed multi-electrode setup, it is possible to position the electrodes along a line perpendicular to the crevice mouth and monitor the current over the different points of the attack. A cross section of the setup indicates the relative locations of the crevice former and MEA, as shown in Figure 2. This is a flush mounted system that gives us similar results to macroscopic observation possible with multi-crevice former assemblies. The main advantage of using MEAs is that they give lateral resolution of the initiation, metastable, and propagation current under the crevice.

Furthermore, by using recently developed Electrochemical Impedance Spectroscopy (EIS) capable multi-electrode array testing equipment, it is possible to use the same multi-electrode setup to monitor the earliest stages of the breakdown or depassivation process by monitoring the evolution of the interfacial impedance at every position. Kehler found that stable crevice corrosion occurred at a critical distance from the crevice mouth for Ni-Cr-Mo alloys 22 and $625 .{ }^{43}$ Crevice corrosion initiation and propagation occurred by passivity breakdown at a row of metastable pits resulting in localized change in the composition of the crevice solution.

Using an array to study crevice corrosion requires the rescaling of the crevice. It is possible to relate the crevice gap to the position of maximum attack using a geometric scaling factor. ${ }^{44}$ The scaling factors, or scaling laws, describe the effect of the crevice geometry on the corrosion behavior inside the crevice. Two factors are usually used, $\mathrm{L} / \mathrm{G}$ or L $\mathrm{L}^{2} / \mathrm{G}$, with $\mathrm{L}$ being either defined as the length of the crevice or the distance between the crevice mouth and $\mathrm{G}$ defined as the crevice gap. Scaling laws derived from experimental data will return an $\mathrm{x}_{\text {crit }}{ }^{2} / \mathrm{G}$ ratio (G: crevice gap, $\mathrm{x}_{\text {crit }}$ : critical distance between initiation line and crevice mouth). Using these scaling laws, a rescaled creviced array can be used to monitor the spatial evolution of the current during the initiation of crevice corrosion. The addition of EIS capabilities should permit the real time observation of the passive film characteristics, enabling changes in oxide film properties to be correlated with initiation of crevice corrosion.

\section{Spreading of Intergranular Corrosion by Cooperative Interactions}

Microscopic investigations of surfaces in solutions that do not typically support intergranular corrosion (IGC), have found that IGC initiates at the bottom of pits that are already formed. ${ }^{45,} 46$ These studies have hypothesized that the highly aggressive solution found at the bottom of pit cavities plays an important role in the initiation of IGC. ${ }^{45,46}$ However, the mechanisms for IGC triggering by pitting were not investigated. Additionally, the processes that trigger rapid lateral IGC spreading across entire 
electrode surfaces along the highly susceptible continuous network of grain boundaries have not been investigated.

Stainless steels are particularly susceptible to intergranular corrosion when they are heated in the range of $538-927^{\circ} \mathrm{C}$, either during improper processing or welding. ${ }^{47}$ Precipitates $\left([\mathrm{Fe}, \mathrm{Cr}]_{23} \mathrm{C}_{6}\right)$ tend to form, when $\mathrm{Cr}$ diffuses to the grain boundaries, leaving immediately adjacent regions $\mathrm{Cr}$ depleted and more susceptible to dissolution than the unchanged grain interior matrix. ${ }^{47}$ This process is known as sensitization. Preferential dissolution takes place at the grain boundaries, while the interior remains passive under specific conditions when: (a) grain boundaries are sensitized, (b) the environment is aggressive enough to enable intergranular attack, and (c) certain regions of the material are in a potential range where it is active. Similar phenomena are also caused by $\mathrm{Cu}$ depletion in $\mathrm{Al}-\mathrm{Cu}$ and $\mathrm{Al}-\mathrm{Cu}-\mathrm{Mg}$ alloys. $^{48}$

In highly acidic environments, stainless steels have an active-passive behavior characterized by an anodic current peak on E-I polarization curves associated with the transition from active to passive behavior. The Flade potential ( $E_{\text {Flade }}$ ) (a.k.a. activation potential) marks the point where a steep rise in dissolution current occurs, when approached from positive potentials. The Flade potential is strongly dependent on the $\mathrm{Cr}$ concentration in $\mathrm{Fe}-\mathrm{Cr}$ alloys, where materials with lower $\mathrm{Cr}$ concentrations have higher Flade potentials. ${ }^{49-51}$ Additionally, the passive current density increases with decreasing $\mathrm{Cr}$ concentration. $^{52}$ Intergranular corrosion occurs when the interfacial potential is lower than the Flade potential of the grain boundaries $\left(E_{\text {Interface }}<E_{\text {Flade }}\right)$. Additionally, a $\mathrm{Cr}$ concentration gradient along grain boundaries may occur, resulting in a range of Flade potentials and earlier initiation of certain grain boundary regions. ${ }^{53}$ MEAs provide an opportunity to study this phenomenon.

\section{METHODS}

Multi-electrode arrays are typically constructed in two different configurations from the desired material (i.e., wire, foil, or electrodeposited dots). The electrodes are typically coated with an insulating coating allowing electrodes to contact one another, in close packed arrangements, while ensuring electrical isolation. The first configuration is far-spaced MEA with spacing that far exceeds the size of the electrodes, as shown in Figure 3a. The far-spaced electrode arrays are used for high throughput type experiments, where large quantities of data are desired, as described above. Additionally, far-spaced electrodes ensure that chemical and potential fields originating from electrodes do not affect adjacent electrodes. Therefore, specimens are chemically decoupled from one another. Large electrodes may be used but small electrodes are easy to contain in one cell yet remain decoupled.

The second configuration is a close packed simple cubic array where all the wires are carefully arranged to ensure the wires were touching in the rectangular orientation, as shown in Figure $3 \mathrm{~b}$. Close packed MEAs are used to simulate planar electrodes, as described above. The size of the electrodes, in the close packed array, is often matched to the size of anode or cathode regions or some other significant corrosion feature.

Both types of arrays are flush mounted in epoxy resin and polished with grinding paper and polishing slurry to the desired finish. Electrodes are placed in a custom electrochemical cell containing a platinum-niobium counter electrode, a remotely placed standard calomel electrode (SCE), and a water circulation coil for solution heating, if needed. The cell can be modified to allow any of three different 
orientations: horizontal face up, horizontal face down, or vertical. One method of potential control can be conducted using a Model 900 Multichannel Microelectrode Analyzer* (MMA) (Scribner Associates, Inc.). The MMA has 100 individually measured zero resistance ammeters (ZRA) that measure the current of each of the coupled electrode elements individually. The MMA has the capabilities of controlling the applied potentiostatic or potentiodynamic potential in ten groups of ten electrodes each. Specific groups of electrodes can be controlled at a desired potential, while monitoring the remaining electrode elements. For instance, rows of electrodes may be initiated or forced to corrode at a high potential or proximate anodes or cathodes may be simulated. The system also has the capability of utilizing local reference electrodes, $\mathrm{pH}$ sensors, or ion selective electrodes to monitor local processes. Additionally, a Model 910 Multichannel Microelectrode Analyzer ${ }^{\dagger}$ (MMA-Z) can conduct Electrical Impedance Spectroscopy sequentially on 100 element MEAs.

\section{Interplay between Water Chemistry and Electrochemical Properties of Copper}

Electrode arrays are ideally suited for the study of persistent anodes and cathodes. In this study, $5 \times 20$ MEAs were constructed from $150 \mu \mathrm{m}$ diameter copper wires with a nominal separation distance of 30 $\mu \mathrm{m}$. Arrays were flush mounted to simulate a planar copper electrode surface. Separately addressable and therefore local galvanic currents, OCP and local AC currents responding to local EIS excitation voltages on a single wire can be separately inventoried and analyzed from each wire in the array. In this way, the factors contributing to potential rise whether associated with significant anode passivity or high cathodic reactivity can be elucidated.

These wires of $150 \mu \mathrm{m}$ diameter are suitable for study when millimeter or micro-millimeter scale separation of anodic and cathodic regions occurs. Each wire is galvanically coupled to the remainder of the wires in the array through a MMA. Therefore, the wire array behaves as one planar electrode simulating the inner diameter of a copper pipe. Since each wire in the array is coupled and the ability exists to inventory total and electrode specific galvanic currents in real time, this method provides the capability to identify formation of persistent anodes (pits) versus switching anodes (uniform attack) as a function of water chemistry variables. The local galvanic current flow, at each wire, can also be assessed as a function of water chemistry and exposure time. This technique is thus able to uniquely study the effects of water chemistry on the development of persistent anodes and cathodes. Single or dual wire electrochemical potential, small amplitude cyclic voltammetry, and EIS experiments can also be conducted on selected groups of wires as a function of water chemistry variables to interrogate their individual properties. Chronoamperometry may be conducted to identified anodes and cathodes to assess local ability to support cathodic reaction kinetics during a single potential step. ${ }^{54,55}$ Thus, a thorough assessment of spatially resolved anode and cathode development and properties may be obtained as a function of water chemistry. Specific water chemistries that promote uniform corrosion (i.e., switchable anodes and cathodes) can be distinguished from those that promote development of persistent anode sites, using this approach. The factors contributing to potential rise may also be elucidated by obtaining detailed understanding of the electrochemical properties of the anodes compared to the cathodes.

Recent research has discovered that higher $\mathrm{pH}(\mathrm{pH}=8$ to $\mathrm{pH}=10)$, higher chlorine $\left(5 \mathrm{ppm} \mathrm{Cl}_{2}\right)$ and higher aluminum ( $2 \mathrm{ppm} \mathrm{Al}$ ) concentration in synthetic potable water could act together to create the conditions to form pits on copper pipe. ${ }^{56}$ To test this hypothesis, closed packed arrays of 100 copper wires of 150

\footnotetext{
* Trade name

${ }^{\dagger}$ Trade name
} 
microns in diameter have been set up in flat cell to simulate the vertical inside of copper surface. According to the reported potable water recipe that promotes pitting, $2 \mathrm{ppm}$ of aluminum in the form of $\mathrm{Al}(\mathrm{OH})_{3}$ is added into the synthetic drinking water, and $\mathrm{pH}$ is adjusted to $9.2 .^{57}$ Under these conditions $\mathrm{Cl}_{2}$ reacts to form hypochlorite ions.

\section{Corrosion Spreading in Concrete}

The traditional approach to assess lateral spread of corrosion damage is determination of a pitting factor. ${ }^{58}$ The pitting factor is the ratio of the maximum pit depth to the average corrosion penetration depth. A pitting factor of 1 is defined as general corrosion and increasing values above 1 indicate increasingly localized attack. However, the pitting factor does not provide the rate of corrosion spreading unless testing is conducted over time. MEAs provide a new technique to examine the lateral corrosion spreading behavior of new rebar alloys compared to conventional carbon steel in an electrolyte that simulates concrete pore solution chemistry. In this manner, insight can be gained into the expected corrosion propagation behavior of new candidate rebar alloys when embedded in concrete. 100 wire (5x20) MEAs were constructed from carbon steel and AISI 316L (UNS S31603) stainless steel to directly observe surface corrosion propagation in both a freely corroding system and surrounding an electrochemically induced active site. In addition, pitting factors were also determined to further characterize the active corrosion morphology of different rebar materials by comparing maximum pit depth to gravimetrically determined uniform corrosion rates from samples where corrosion was galvanostatically propagated..$^{59}$

\section{Crevice Corrosion}

MEAs, with a configuration of $5 \times 20$, were constructed from $250 \mu \mathrm{m}$ diameter AISI 316 (UNS S31600) stainless steel wire. For the study of crevice corrosion, typical MEAs had to be modified. First, the array needs to be fitted to support the attachment of a crevice former. Second, the covered metal area/crevice area must be large enough to develop an aggressive crevice solution necessary for the crevice corrosion initiation. To obtain a large covered metal area/crevice volume ratio, typical of actual crevices, the grooved plastic, epoxy, or glass encasing usually used to mount the close packed electrode array ${ }^{6}$ was replaced by a $2.54 \mathrm{~cm}$ cylindrical metallic encasing, providing a continuous metal surface. The metal was chosen to be the same as that of the electrodes. In this case, the encasing was AISI 316 stainless steel. The $5 \times 20$ array was set inside a machined groove, in the metallic casing, using heat-cured epoxy. As shown in Figure 4b, the resulting electrode mimics a planar metallic specimen except that the array enables regions of the crevice to be separately addressed for detailed electrochemical information.

Two methods for controlling the crevice gap have been used. The more traditional approach is to apply a set torque to a crevice former. ${ }^{40,60}$ The higher the torque the tighter the crevice gap. ${ }^{61}$ The crevice gap can also be controlled by either inserting thin films, as shims, between the sample surface and the crevice former (crevice gap above $25 \mu \mathrm{m})^{62}$ or by using micro-fabricated crevice formers using semiconductor device manufacturing techniques (crevice gap lower than $10 \mu \mathrm{m}$ ). ${ }^{44}$ In this study, torqued Delrin (trade name) crevice formers were used. The setup eventually can be used with shims as well. The cross section of the crevice former setup used and a picture of the configuration of the MEA, in the solid encasing, are shown in Figure 4. The Delrin crevice former is supported by a threaded rod, screwed into the array encasing. A coupled concave-convex assembly permits compensation for any difference in perpendicularity between the surface and the rod (due to polishing and machining) and ensures that the crevice former was parallel to the MEA surface, as shown in Figure 4. 
With the dimensions used $(250 \mu \mathrm{m}$ diameter wires, encasing $2.54 \mathrm{~cm}$ diameter and $2.5 \mathrm{~mm}$ wide groove and crevice former of $2.54 \mathrm{~cm}$ diameter) the metal area/crevice volume ratio was calculated and compared to that of a conventional planar electrode and an array with no metal encasing. For a crevice gap of $1 \mu \mathrm{m}$, the ratio is $9.5 \times 10^{3} \mathrm{~cm}^{-1}$ for the experimental crevice setup compared to $10^{4} \mathrm{~cm}^{-1}$ for a conventional crevice sample and $211 \mathrm{~cm}^{-1}$ for a similar setup without metallic encasing. This confirms that an array encased in a similar material to the electrodes of the dimensions used will provide a reactive geometry extremely close to that of a conventional planar electrode.

Stepped potentiostatic experiments have been used, to study the initiation, stabilization, propagation, and stifling of crevice corrosion. Experiments were performed in $0.6 \mathrm{M}$ and $1 \mathrm{M} \mathrm{NaCl}$ under aerated conditions at ambient or elevated temperature. At first, short steps (a few hours long) of $50 \mathrm{mV}$ or more were applied. Potentiostatic steps evolved towards longer steps (1 day) at lower potentials (as low as $25 \mathrm{mV}$ ). Longer steps are expected to help in reaching crevice stability, at each potential. With smaller potential steps, crevice corrosion should be observed to develop gradually. Long potentiostatic step experiments were preceded by initial exposure at OCP. This was done to permit the creation of a passive film that would be stable during the potential steps, therefore, reducing the effect of the passive film aging during crevice corrosion. The stainless steel encasing was kept at low anodic potentials to provide a passive current, which contributes to the formation of a critical crevice solution. The current for each wire was monitored during the course of all experiments. In certain cases, EIS was conducted on certain wires.

The influence of the proximate cathode on crevice corrosion initiation and propagation is also under investigation. In this case, all or a selection of the wires outside the crevice were kept at a low cathodic potential $\left(-400 \mathrm{mV}_{\mathrm{SCE}}\right)$ simulating cathodic polarization and associated $\mathrm{OH}^{-}$production when a cathode is nearby.

\section{Spreading of Intergranular Corrosion by Cooperative Interactions}

MEAs were constructed from $150 \mu \mathrm{m}$ AISI 304 (UNS S30400) stainless steel wires that were heat treated at $1030^{\circ} \mathrm{C}$ for 1 hour to solutionize the material and $621^{\circ} \mathrm{C}$ for 48 hours to sensitize the material. ${ }^{63}$ The chemical composition of the $304 \mathrm{SS}$ used was: $0.055 \% \mathrm{C}, 18.09 \% \mathrm{Cr}, 1.54 \% \mathrm{Mn}, 0.09 \% \mathrm{Ni}$, $0.027 \% \mathrm{P}, 0.53 \% \mathrm{Si}, 0.012 \% \mathrm{~S}$, and the balance Fe. For comparison, as-received material that did not undergo any heat treatment was used. The non-sensitized wires had an average ASTM grain size of 14 while the sensitized wires had an average ASTM grain size of 7.6. The degree of sensitization (DOS) for both the non-sensitize and sensitized materials were determined by ASTM G108 in $0.5 \mathrm{M} \mathrm{H}_{2} \mathrm{SO}_{4}+$ $0.01 \mathrm{M} \mathrm{KSCN}$ at $30^{\circ} \mathrm{C}$. The DOS for the non-sensitized material was determined to be 0.164 coulombs $/ \mathrm{cm}^{2}$ while the sensitized material had a DOS of 56.5 coulombs $/ \mathrm{cm}^{2}$. Both far spaced $(3 \times 4)$ and close packed (5x20) MEAs were constructed from the sensitized 304 SS material.

Cooperative interaction experiments were conducted in $0.06 \mathrm{M} \mathrm{HCl}+0.01 \mathrm{M} \mathrm{KSCN}$ at $60^{\circ} \mathrm{C}(\mathrm{pH} 1.22)$ to simulate the environment that is enhanced in both $\mathrm{H}^{+}$and $\mathrm{Cl}^{-}$ions produced adjacent to actively pitting sites. It is hypothesized that both IR potential drop and solution enhancement are required for cooperative growth of IGC along $\mathrm{Cr}$-depleted grain boundaries. 
Cooperative growth experiments were conducted on close spaced MEAs constructed from sensitized 304. SS $5 \times 20 \mathrm{MEAs}$ in $0.06 \mathrm{M} \mathrm{HCl}+0.01 \mathrm{M} \mathrm{KSCN}$ at $60^{\circ} \mathrm{C}$. The first two rows of the close packed array were held at a potential $\left(+1 \mathrm{~V}_{\mathrm{SCE}}\right)$ high enough to cause stable pitting. The remaining electrodes (rows 3 to 20) in the MEA were potentiostatically held at $\mathrm{E}=-0.29 \mathrm{~V}_{\mathrm{SCE}}$ in the passive range $\left(\mathrm{E}>\mathrm{E}_{\mathrm{Flade}}\right)$. During the duration of the 20 minute potentiostatic hold under these conditions, the current was monitored for all 100 wires on the MEA. The anodic charge passed was calculated from current-time curves for each wire of the MEA that was held in the passive range. Charge density was also used to detect the onset of IGC behavior with time. A limited number of experiments were conducted where all the electrodes were potentiostatically held for 20 minutes at a potential in the passive range $\left(-0.29 \mathrm{~V}_{\mathrm{SCE}}\right)$ $\left(E_{\text {Applied }}>E_{\text {Flade }}\right)$ and no electrodes were initiated. These experiments were conducted to show that interactions do not occur without pitting and associated ohmic potential drop, as well as possible solution enhancement.

\section{RESULTS AND DISCUSSION}

\section{Key Advantages of High Throughput Testing}

One of the key uses of MEAs is the ability to conduct high throughput testing. This is particularly useful in Materials Science when materials informatics is desired or when a property is governed by a statistical distribution of flaws. ${ }^{64}$ A good example is the pitting potential of engineering alloys which is often governed by the statistical distribution of flaws on the surface area tested. Therefore, often variations in the distribution of flaws from one electrode to the next exist. Large numbers of E-log $i$ curves can be obtained in reasonable time periods using MEAs. Instead of reporting single values, such as the average or median, to represent a complex population, the entire data set can be presented by cumulative probability curves. Such curves can elicit information about the population distribution behavior (i.e., normal, skewed, or bimodal) of specific electrochemical parameters. Through the type of distribution, such a plot can reveal whether there are single or multiple underlying causes for such electrochemical behavior. ${ }^{64}$ Such population distributions can also give important information in the underlying microstructure effects on specific electrochemical behavior. For example, the pitting potential of AISI 316 stainless steel in $1 \mathrm{M} \mathrm{NaCl}$ solutions at $47^{\circ} \mathrm{C}$ is statistically distributed and depends strongly on the $\mathrm{pH}$, as shown in Figure 5. Here, over $50 \mathrm{E}$-log i curves were acquired with far spaced MEAs for each $\mathrm{pH}$ condition. At low $\mathrm{pHs}$, the data set is approximately normally distributed, indicated by the straight line behavior. The wide distribution in $\mathrm{E}_{\mathrm{pit}}$ reflects the statistical differences in inclusions from one electrode to the next that govern the pitting potential. However, a second population distribution emerges as the $\mathrm{pH}$ decreases. The population distribution shifts to non-normal behavior at $\mathrm{pH} 3$ and more prominently at $\mathrm{pH}$ 1.8. A clear bimodal distribution is observed at $\mathrm{pH} 1.8$. Clearly two distinct populations of flaws exist, each with their own statistical variation that governs pitting potential. The shift in cumulative probability curve, at $\mathrm{pH} 3$, to lower pitting potentials can be explained by the thermodynamic stability of $\mathrm{MnS}$ inclusions which begin to dissolve at $\mathrm{pH} 4.8$. The dissolution of $\mathrm{MnS}$ inclusions leads to easy pit formation on the subset of electrodes with many large $\mathrm{MnS}$ inclusions. The unaffected portion of the bimodal distribution can be attributed to a second population of initiation sites that is more resistant to low $\mathrm{pH}$, such as $\mathrm{CrS}$ or TiS. The difference between these two distributions in flaws is much more prominent at $\mathrm{pH} 1.8$. In fact, a small population of TiS inclusions was found in this alloy. High throughput testing can elicit valuable information about the material's microstructure that would otherwise be hidden by low numbers of samples or by the use of single statistical values. This approach also has the benefit to corrosion mitigation where it is useful 
to uncover whether a pretreatment or inhibitor has the greatest effect on the entire population of flaws or on a certain subset.

\section{Interplay between Water Chemistry and Electrochemical Properties of Copper}

Starting from $0 \mathrm{ppm}$, free chlorine was increased by $1 \mathrm{ppm}$ per day to $5 \mathrm{ppm}$ by adding reagent grade $\mathrm{NaOCl}$ into test drinking water and tested by $N, N^{\prime}$-Diethylphenylenediamine (DPD) colorimeter. Results show that before $5 \mathrm{ppm}$ free chlorine is added in the test drinking water, only uniform passive dissolution of copper occurs with a current density less than $5 \mu \mathrm{A} / \mathrm{cm}^{2}$. After $5 \mathrm{ppm}$ free chlorine is added, the OCP gradually increases above a critical level, which is about $100 \mathrm{mV}_{\mathrm{SCE}}$ within a certain time (Figure 6). Then it suddenly drops to a very low level (about $75 \mathrm{mV}_{\text {SCE }}$ ) in very short time (less than 1 minute). The pitting potential of copper in potable water has been historically defined as 100 $\mathrm{mV}_{\mathrm{SCE}}{ }^{65}$ The current maps corresponding to these two times (denoted on OCP figure) show that before the OCP reaches the critical level, only uniform passive dissolution of copper occurs. However when the OCP drops to a very low level, a dark square in the current maps indicates a current density about 70 $\mu \mathrm{A} / \mathrm{cm}^{2}$ averaged over the entire wire (if the pit area is $1 / 10^{\text {th }}$ of wire surface the current density is 700 $\mu \mathrm{A} / \mathrm{cm}^{2}$ ). The high current density confirms that a strong anode is forming. The current versus time curve for the strong anode wire during the whole test is shown in Figure 7 . Corresponding to the potential drop of OCP, an abrupt increase of current density occurs from $5 \mu \mathrm{A} / \mathrm{cm}^{2}$ (uniform attack) to about $50 \mu \mathrm{A} / \mathrm{cm}^{2}$ (localized attack). This strong anode lasts to the end of the test, 12 hours, although the magnitude decreases over time, while the currents on other passive wires remain between -5 and +5 $\mu \mathrm{A} / \mathrm{cm}^{2}$. We interpret this result as evidence that persistent anode is forming on one single wire in this water chemistry. In total, 9 wires form persistent anodes one after another during the 24 hours test but only at the $5 \mathrm{ppm} \mathrm{Cl}_{2}$ level.

\section{Corrosion Spreading in Concrete}

It was seen that corrosion spread rapidly across the surface from active sites on carbon steel, while stainless steel demonstrated complete resistance to spreading from preferentially initiated sites. An example of corrosion spreading behavior on carbon steel and AISI 316L stainless steel (UNS S31603) 100 wire $(5 \times 20)$ MEAs is shown in Figure 8. Carbon steel held at $0.2 \mathrm{~V}_{\mathrm{SCE}}$ displayed active corrosion that initiated quickly and spread rapidly over the entire MEA surface in less than 2000 seconds. 316L stainless steel showed no corrosion spreading from preferentially active sites (held at $1 \mathrm{~V}_{\mathrm{SCE}}$ ) on to surrounding electrodes (held at $0.2 \mathrm{~V}_{\mathrm{SCE}}$ ) despite a considerably more aggressive testing environment. Moreover, the preferentially active sites resisted initiation and did not fully activate until approximately 11000 seconds. It can be seen from these results that the length and spreading of corrosion along the electrode surface is greatly influenced by the material composition. The length (L) and depth (X) of corrosion attack both must be considered to assess the impact of rebar corrosion on concrete cracking. ${ }^{39}$ Electrochemical testing on MMA's provides the ability to discretely assess the length of corrosion spreading at the electrode surface. Studies indicate that when $\mathrm{L}$ is small $\mathrm{X}$ must be large in order for $\mathrm{X} \square \mathrm{X}_{\text {crit. }}$ Therefore, stainless steel rebar should be much less likely to spall and crack concrete if corrosion is initiated.

\section{Crevice Corrosion}


The initiation and spreading of crevice and pitting corrosion occur with time, as shown in Figure 9. The current for each individual electrode under the crevice former, in the MEA, was monitored during the course of the experiment, as shown in Figure 9. Even within the scope a single simple test, the array provides a wealth of information. The critical crevice initiation current can be found as well as the location of crevice initiation, the propagation rate and the depth of attack (as detailed below).

It is possible to include localized electrochemical variation, such as proximate cathode, that would exist on a real electrode where the cathode was nearly. The initiation and spreading of two electrochemical variations is compared, as shown in Figure 10: a) the entire MEA was held potentiostatically at 100 $\mathrm{mV}_{\mathrm{SCE}}$ and $\mathrm{b}$ ) the inside of the crevice is kept at $100 \mathrm{mV}_{\mathrm{SCE}}$ while the outside acts as a proximate cathode $\left(-400 \mathrm{mV}_{\mathrm{SCE}}\right)$. We can observe in Figure 10a. and $\mathrm{b}$. that the crevice corrosion initiates close to the crevice mouth and spreads into the crevice. At the same time, pitting corrosion initiates outside. A proximate cathode inhibits the propagation of the attack, presumably due to the $\mathrm{OH}^{-}$production, as shown in Figure 10b. At $t=0$, only a few wires are initiated and, after one hour the number of wires that have initiated increases for the case with a proximate cathode. In the absence of a proximate cathode the crevice is fully initiated after 1 hour. Existing crevice corrosion investigation methods (non-multielectrode experiments), described previously, would only have allowed proximate cathodes to be introduced by changing the size of the external cathode. Furthermore, it is possible and easy to change the size, position and potential of such a cathode to replicate electrochemical conditions.

The evolution of the calculated average depth of attack with time, is shown in Figure 11. MEAs were potentiostatically stepped at $50 \mathrm{mV}$ per day, after being aged for 3 days at OCP (final $E_{\text {corr }}$ value was $-75 \mathrm{mV}$ SCE) so the passive film would not evolve dramatically during the measurement. The attack depth is calculated using equation 6 , with $\square \mathrm{d}(\mathrm{t})$ the depth variation at a time $\mathrm{t}, \mathrm{Q}(\mathrm{t})$ being the charge at a time $\mathrm{t}$, EW the equivalent weight of the alloy, $F$ the Faraday constant, $\square$ the density of the alloy and A the area of the electrode.

$$
\Delta d(t)=\frac{Q(t)^{*} E W}{F^{*} \rho^{*} A}
$$

The charge is derived from the current measured over time. The plotted average depth of attack for one column is the average of the derived depth of attack of the five rows at that particular column, as shown in Figure 11.

As was suggested by Kehler and Scully ${ }^{43}$, stable crevice corrosion initiates at a critical distance from the crevice mouth. This critical distance was found to be between $0.5 \mathrm{~mm}$ and $0.8 \mathrm{~mm}$ from the crevice mouth depending on crevice gap. The crevice attack depth increases at a faster rate close to the mouth than at the end of the crevice. The maximum depth reached is $0.45 \mathrm{~mm}$ after 7.5 hours at $100 \mathrm{mV}$ SCE. The attack did not initiate until 5 hours into the test giving a rate of $0.18 \mathrm{~mm}-\mathrm{hr}^{-1}$. The slowest rate was found at the deepest end of the crevice with a maximum attack depth of $0.22 \mathrm{~mm}$, equivalent to a rate of $0.9 \mathrm{~mm}-\mathrm{hr}^{-1}$, half of that at the crevice mouth. Such information would be difficult to obtain with the use of multi-electrode arrays.

\section{Spreading of Intergranular Corrosion by Cooperative Interactions}


In the study of intergranular corrosion of sensitized stainless steels, it is hypothesized that both potential drop and concentration changes could trigger intergranular corrosion on adjacent surfaces, prone to intergranular attack, in concentrated acids. During pitting corrosion, the potential drop prevents further pitting (i.e., inhibits pit activity) in the immediate vicinity of an active pit site. The resulting concentration and surface damage effects enhance the formation of new pits. ${ }^{2-6}$ In contrast, intergranular attack is expected to spread from initial pit sites in specific patterns related to the local acid concentration and potential drop. In this case, both potential drop and electrolyte concentration are expected to trigger attack. Intergranular corrosion is expected to be triggered if: (a) grain boundaries are sensitized, (b) the environment becomes aggressive enough to enable intergranular attack and (c) an ohmic potential drop occurs such that the potential across the double layer drops below the Flade potential for the particular grain boundary composition.

Local accumulation of aggressive species associated with the acid/halide model has been shown to cause enhancement of pitting adjacent to previously active pit sites. ${ }^{2-6,66}$ As hydrolysis takes place during intergranular corrosion, the local $\mathrm{H}^{+}$and $\mathrm{Cl}^{-}$ion concentrations increase. The local decrease in $\mathrm{pH}$ causes an increase in the Flade potential (as discussed above), causing the material to be more susceptible to intergranular corrosion at potentials typically in the passive region. ${ }^{49,50,52,67,68}$ If the ${ }^{\circ} \mathrm{Cl}^{-}$ ion concentration is increased due to accumulated aggressive species, then the pitting potential may fall near the Flade potential, resulting in pitting instead of or concurrently with intergranular corrosion.

The active-passive behavior of the grain boundary sensitized AISI 304 SS material, shown in Figure 12a, indicates the potential range where intergranular corrosion occurs. A closer look at the active passive transition region of the E-I curve indicates the specific region where IGC is expected, as shown in Figure 12b. If the applied potential is within the passive range, the ohmic potential can reduce the interfacial potential below the potential for IGC initiation $\left(\mathrm{E}_{\text {Interfacial }}<\mathrm{E}_{\text {Flade }}\right.$ for the grain boundaries), at grain boundaries adjacent to active pit sites. A drop in the local potential $\left(\mathrm{E}_{\text {Interfacial }}<\mathrm{E}_{\text {Flade }}\right)$ would be expected to trigger intergranular corrosion. Newman's solution predicts that ohmic potential drop will reduce the interfacial potential into a range where intergranular corrosion can occur, as shown in Figure $13{ }^{28}$ Using the calculated interfacial potential and the true E-I polarization curve expressing the true interfacial kinetics (Figure 12), the resulting current can be predicted, as shown in Figure 13. Ignoring aggressive species effects, a region of intergranular corrosion can be predicted, as shown in Figure 13. As the distance from the active row increases, the ohmic potential drop decreases placing different rows at different points along the active passive nose (Figure 13) triggering intergranular corrosion.

The trigger and cooperative growth of IGC was observed in induced interaction experiments, as shown in Figure 5. In these experiments, the first two rows of the electrode (rows 1 and 2) were held at a potential where pitting was induced $\left(+1 \mathrm{~V}_{\mathrm{SCE}}\right)$. The remainder of the electrode elements were held in the passive range $\left(-0.29 \mathrm{~V}_{\mathrm{SCE}}\right)$. A distinct intergranular corrosion pattern was observed, in optical photomicrographs, after 1200 seconds (Figure 14). Corrosion is observed in five distinct zones of intergranular corrosion damage: 1) row 3-minimal damage, 2) rows 4 to 5 -intermediate damage (Figure $15 \mathrm{a}), 3$ ) rows 5 to 10 -significant damage (Figure 15b), 4) row 11-intermediate damage (Figure 15c), and 5) rows 12 to 20 -minimal damage (Figure 15d). This distinct IGC damage pattern closely matches the zones of damage predicted by calculations using Newman's solution and E-I kinetics (calculations were based on $\mathrm{i}=1.25 \mathrm{~A} / \mathrm{cm} 2$ and $\mathrm{K}=0.027 \Omega^{-1}-\mathrm{cm}^{-1}$ ). The ohmic potential drop, induced by actively pitting electrodes, shifts the true applied potential of the $1^{\text {st }}$ row below the active passive nose (Figure $3 \mathrm{~b}$ ) to a potential where the dissolution current is significantly lower than the maximum active current. The 
ohmic potential drop decreases, as the distance from the actively pitting rows increases, placing different rows at different points along the active passive nose. As a result, different levels of IGC are observed that are dictated by the active passive nose behavior. Farther away from the active rows, the accumulated intergranular corrosion damage decreases. The applied potential, far from the active rows, has a negligible contribution from ohmic potential $\left(\mathrm{E}_{\text {applied/measured }}=\mathrm{E}_{\text {Interfacial }}\right)$ resulting in minimal IGC damage, characteristic of passive dissolution.

The current associated with intergranular dissolution of each electrode was monitored during the course of the 1200 second experiment. The accumulated charge due to intergranular dissolution of each electrode element was determined as a function of distance, from the active pitting row, and time, as shown in Figure 16. The accumulated charge corresponds well with the accumulated damage, observed in optical photomicrographs (Figure 14). It is evident that the region of high accumulated anodic charge broadens and shifts with time indicating that the accumulated IGC damage region spreads across the electrode surface. The spread of IGC damage can also be observed in stationary current maps, which signify the current value at an instant in time by color, of individual electrodes, at specific times, as shown in Figure 17. Low stationary currents are observed, at early times (60 seconds), which extend from 3 to 7 rows away from the active rows. The amount of stationary anodic current increases, as indicated by darkening of the red current scale, as time progresses to longer times (120 seconds). After 120 seconds, not only does the stationary current increase but the region of high anodic current spreads further from the actively pitted rows. These results clearly indicate that intergranular corrosion can be triggered by pitting. Additionally, 'after initial triggering, intergranular corrosion was found to spread beyond regions of suspected ohmic potential drop affects, due to accumulated aggressive species that further increase the susceptibility of $\mathrm{Cr}$ depleted grain boundaries. These results confirm that cooperative interactions, caused by pitting behavior, can trigger a transition from pitting to IGC and continued IGC spreading when: a) the material was sensitized, b) there was IR drop, and c) solution enhancement occurred.

\section{SUMMARY}

Multi-electrode arrays are powerful tools in the investigation of local behavior of corrosion sites of global corrosion phenomena. The ability to measure the current for individual electrode elements allows spatial and temporal measurements to be conducted simultaneously. The ability to interrogate each electrode, under open circuit conditions, allows the identification of persistent anodes on $\mathrm{Cu}$ surfaces. These persistent anodes can develop into aggressive pitting sites that cause premature failure of copper pipes. It is demonstrated that MEAs allow the investigation of the effects of small changes in solution chemistry on anode development.

The investigation of carbon steel in simulated concrete pore solution near or at the critical chloride concentration indicates that a limited number of sites initiate at first and trigger global depassivation of the entire electrode surface. In contrast, $316 \mathrm{~L}$ stainless steel, once pitted at local sites, fails to trigger global depassivation or corrosion growth even under much more aggressive conditions. These findings support the replacement of standard carbon steel rebar, in concrete, with more corrosion resistant alloys. According to these results, a finite anode length will reduce the propensity for concrete spalling.

It is demonstrated that MEAs can also be used in the investigation of crevice corrosion. MEAs allow the monitoring of regions of electrode surfaces that are located within the crevice and outside the 
crevice. It was found that, under conditions where the potential inside and outside the crevice were equal, crevice corrosion initiates near the crevice mouth and grows into the crevice. If the region outside the crevice is forced to be a proximate cathode, simulating a nearby cathode, such as in real world situations that lack a potentiostat, then only a few anodic sites grow within the crevice area and the majority of the crevice remains non-corroded.

MEAs play a critical role in the investigation of the trigger and spreading of intergranular corrosion on sensitized stainless steels. Pitting corrosion was found to trigger intergranular corrosion on adjacent regions if: a) the material was sensitized, b) ohmic potential drop occurred, and c) solution enhancement occurred. Once IGC was triggered, IGC spread from regions of intense accumulated IGC damage to regions that were predicted not to support IGC based at electrochemical conditions without interactions. This spreading is believed to occur due to mechanisms associated with active dissolution of $\mathrm{Cr}$ depleted grain boundaries.

\section{ACKNOWLEDGEMENTS}

This concrete project was sponsored by the VTRC (Virginia Transportation Research Council). The support and helpful discussions with Dr. Gerardo Clemenal and Dr. Steve Sharp are gratefully acknowledged. The crevice corrosion work was supported by the Office of Science and Technology International (OST\&I), Office of Civilian Radioactive Waste Management, U.S. Department of Energy. Dr. Harold T. Michels and Copper Development Association Inc. provided financial support for pitting of $\mathrm{Cu}$ studies. The United States Department of Energy, Office of Basic Energy Sciences, Division of Materials Sciences and Engineering supported intergranular corrosion studies under contract DEFG0200ER45825 with Jane Zhu as contact monitor. Special thanks to Scribner Associates, Inc. for instrument and software support.

\section{REFERENCES}

1. H. S. Isaacs,"The Effect of Height on the Current Distribution Measured with a Vibrating Electrode Probe", J. Electrochem. Soc., vol. 138,No. 3 (1991): p. 722-728.

2. N. D. Budiansky, J. L. Hudson and J. R. Scully, Origins of Persistent Interactions Among Localized Corrosion Sites, Symposium in Honor of Hans Bohni, PV2002-24, 133-146, (Salt Lake City, UT, Electrochemical Society, 2002).

3. N. D. Budiansky, J. L. Hudson and J. R. Scully,"Origins of Persistent Interactions among Localized Corrosion Sites on Stainless Steel", J. Electrochem. Soc., vol. 151,No. 4 (2004): p. B233-B243.

4. T. T. Lunt, J. R. Scully, V. Brusamarello, A. S. Mikhailov and J. L. Hudson,"Spatial Interactions among Localized Corrosion Sites. Experiments and Modelling", J. Electrochem. Soc., vol. 149, No. 5 (2002): p. B163-B173.

5. T. T. Lunt, S. T. Pride, J. R. Scully, J. L. Hudson and A. S. Mikhailov,"Cooperative Stochastic Behavior in Localized Corrosion. II. Experiments", J. Electrochem. Soc., vol. 144,No. 5 (1997): p. 1620-1629.

6. T. T. Lunt, V. Brusamarello, J. R. Scully and J. L. Hudson,"Interactions among Localized Corrosion Sites Investigated with Electrodes Array", Electrochem. Solid-State Lett., vol. 3,No. 6 (2000): p. 271-274. 
7. V. F. Lucey,"Developments Leading to the Present Understanding of the Mechanisms of Pitting Corrosion of Copper", Br. Corros. J., vol. 7(1972): p. 36-41.

8. Y. Tan,"The Effects if Inhomogeneity in Organic Coatings on Electrochemical Measurements Using a Wire Beam Electrode. Part I", Progess in Organic Coatings, vol. 19(1991): p. 89-94.

9. Y. Tan, Wire Beam Electrode: A New Tool for Localized Corrosion Studies, Australian Corrosion Association Corrosion and Prevention 97, Paper No. 52, (Australia, Australian Corrosion Association, 1997).

10. Y. Tan,"Monitoring Localized Corrosion Processes and Estimating Localized Corrosion Rates Using a Wire Beam Electrode", Corrosion, vol. 54,No. 5 (1998): p. 403-413.

11. Y. Tan and Y. Shiti,"The Effects if Inhomogeneity in Organic Coatings on Electrochemical Measurements Using a Wire Beam Electrode. Part II", Progess in Organic Coatings, vol. 19(1991): p. 257-263.

12. Y.-J. Tan,"A Novel Crevice Corroison Experiment Using A Wire Beam Electrode", The Journal of Corrosion Science and Engineerign, vol. Volume 1 Paper 17(1999.

13. Y. J. Tan,"A New Crevice Corrosion Testing Method and its Use in the Investigation of OIl Stain", Corros. Sci., vol. 50,No. 4 (1994): p. 266-269.

14. Y. J. Tan, S. Bailey, B. Kinsella and A. Lowe,"Mapping Corrosion Kinetics Using the Wire Beam Electrode in Conjuction with Electrochemical Noise Resistance Measurements", J. Electrochem. Soc., vol. 147,No. 2 (2000): p. 530-539.

15. Y.-J. Tan, S. Bailey and B. Kinsella,"Mapping Non-Uniform Corrosion Using the Wire Beam Electrode Method. II. Crevice Corroiosn and Crevice Corrosion Exemption", Corros. Sci., vol. 43(2001): p. 1919-1929.

16. Y.-J. Tan, S. Bailey and B. Kinsella,"Mapping Non-Uniform Corrosion Using the Wire Beam Electrode Method. III. Water Line Corrosion", Corros. Sci., vol. 43(2001): p. 1931-1937.

17. Y.-J. Tan, S. Bailey and B. Kinsella,"Mapping Non-Uniform Corrosion Using the Wire Beam Electrode Method. I. Multiphase Carbon Dioxide Corrosion." Corros. Sci., vol. 43(2001): p. $1905-$ 1918.

18. W. Wang, I. Z. Kiss and J. L. Hudson,"Experiments on Arrays of Globally Coupled Chaotic Electrochemical Oscillators: Synchronization and Clustering", Chaos, vol. 10,No. 1 (2000): p. 248256.

19. S. S. Wang,"Microelectrode Arrays for Lubrication Studies", J. Electrochem. Soc., vol. 136,No. 3 (1989): p. 713-715.

20. S. Zhang, T. Shibata and T. Haruna,"Inhibition effect of metal cations to intergranular stress corrosion of sensitized stainless Steel", Corros. Sci., vol. 47(2005): p. 1049-1061.

21. Q. Zhong;"Study of Corrosion behavior of Mild Steel and Copper in Thin Film Salt Solution Using the Wire Beam Eleactrode", Corros. Sci., vol. 44(2002): p. 909-916.

22. A. J. Bard, F.-R. F. Fan, J. Kwak and O. Lev,"Scanning Electrochemical Microscopy: Introduction and Principles", Analytical Chemistry, (1989): p. 132.

23. T. E. Lister, A. W. Glenn and P. J. Pinhero, Mapping Corrosion in Real-Time, Development of the Microelectrode Array Microscope, Corrosion/2004, Paper No. 04445, (Houston, TX, NACE International, 2004).

24. T. Shibata and Y.-C. Zhu,"The Effects of Film Formation Potential on the Stochastic Processes of Pit Generation on Anodized Titanium", Corros. Sci. , vol. 36,No. 1 (1994): p. 153-163.

25. J. E. Sweitzer, J. R. Scully, R. A. Bley and J. W. P. Hsu,"Nanocrystalline $\mathrm{Al}_{8} 7 \mathrm{Ni}_{8.7} \mathrm{Y}_{4.3}$ and $\mathrm{Al}_{90} \mathrm{Fe}_{5} \mathrm{~Gb}_{5}$ Alloys that Retain the Localized Corrosion Resistance of the Amorphous State", Journal of Electrochemical Society Electrochemical and Solid State Letters, vol. 2,No. 6 (1999): p. 267-270. 
26. G. S. Frankel,"The Growth of 2-D Pits in Thin Film Aluminum", Corros. Sci. , vol. 30,No. 12 (1990): p. 1203-1218.

27. J. R. Galvele,"Transport Processes and the Mechanism of Pitting of Metals", J. Electrochem. Soc., vol. 123,No. 4 (1976): p. 464-474.

28. J. Newman,"Current Distribution on a Rotating Disk Below the Limiting Current", J. Electrochem. Soc., vol. 113,No. 12 (1966): p. 1235.

29. G. Butler, C. K. Ison and A. D. Mercer,"Some Important Aspects of Corrosion in Central Heating Systems", Br. Corros. J., vol. 6(1971): p. 31-38.

30. H. S. Carslaw and J. C. Jaeger, Conduction of Heat in Solids, (New York: Oxford University Press, 1978),

31. L. Organ, J. R. Scully, A. S. Mikhailov and J. L. Hudson,"A Spatiotemporal Model of Interactions Among Metastable Pits and the Transition to Pitting Corrosion", Electrochim. Acta, vol. Accepted for Publication(2005.

32. P. Fernandes,"Type I pitting if copper tunes from a water distribution system", Engineering Failure Analysis, vol. 5,No. 1 (1998): p. 35-40.

33. M. Edwards,"The pitting corrosion of copper", Journal AWWA, vol. July(1994): p. 74-90.

34. T. Fujii,"The effect of water quality on pitting corrosion of copper tube in hot soft water", Corros. Sci., vol. 24,No. 10 (1984): p. 901-902.

35. Y. Feng,"The corrosion behavior of copper in neutral tap water. Part I: corrosion mechanisms", Corros. Sci., vol. 38,No. 3 (1996): p. 369-385.

36. A. Bentour, S. Diamond and N. S. Berke, Steel Corrosion in Concrete, (London: E \& FN Spon, an imprint of Chapman \& Hall, 2-6 Boundary Row, London SE1 8HN, UK, 1997),

37. K. Tuutti, Corrosion of Steel in Concrete, (Stockholm: Swedish Cement and Concrete research Institute, 1982),

38. M. F. Hurley and J. R. Scully, Chloride Threshold Levels in Clad 316L and Solid 316LN Stainless Steel Rebar, Corrosion '02, (Denver, CO, NACE International, 2002).

39. A. A. Torres-Acosta and A. A. Sagues, Concrete Cover Cracking with Localized Corrosion of Reinforcing Steel, Fifth CANMET/ACI, 591-612, (Barcelona, Spain, ACI International, 2000).

40. G78-01: Standard Guide for Crevice Corrosion Testing of Iron-Base and Nickel-Base Stainless Alloys in Seawater and Other Chloride-Containing Aqueous Environments, vol. 3, Annual Book of ASTM Standards, ASTM, 2003),

41. G61-86: Standard Test Method for Conducting Cyclic Potentiọdynamic Polarization Measurements for Localized Corrosion Susceptibility of Iron-, Nickel-, or Cobalt-Based Alloys, vol. 3, Annual Book of ASTM Standards, ASTM, 2003),

42. S. Tsujikawa, Critical Depth for Initiation of Growing Crevice Corrosion, Critical Factors in Localized Corrosion, (Phoenix, Arizona, ECS, 1991).

43. B. A. Kehler and J. R. Scully,"Role of Metastable Pitting in Crevices on Crevice Corrosion Stabilization in Alloys 625 and 22", Corrosion, vol. 61,No. 7 (2005): p. 665-684.

44. J. S. Lee, M. L. Reed and R. G. Kelly,"Combining Rigorously Controlled Crevice Geometry and Computational Modeling for Study of Crevice Corrosion Scaling Factors", J. Electrochem. Soc., vol. 151,No. 7 (2004): p. B423-B433.

45. K. Kowal, J. DeLuccia, J. Y. Josefowicz, C. Laird and G. C. Farrington,"In Situ Atomic Force Microscopy Observations of the Corrosion Behavior of Aluminum-Copper Alloys", J. Electrochem. Soc., vol. 143,No. 8 (1996): p. 2471-2481.

46. V. Guillaumin and G. Mankowski,"Influence of Overaging Treatment on Localized Corrosion of AL 6056", Corrosion, vol. 56,No. 1 (2000): p. 12-23. 
47. A. J. Sedriks, Corrosion of Stainless Steels, T. E. Society, (Ed.), (Princeton, NJ: A WileyInterscience Publication John Wiley \& Sons, Inc., 1996),

48. B. J. Connoly and J. R. Scully, The Transition From Localized Corrosion to SCC in An Al-Li-CuAg Alloy, Corrosion 2002, NACE, 2002).

49. K. Osozawa, K. Bohnenkamp and H. J. Engell,"Potentiostatic Study on the Intergranular Corroison of an Austenitic Chromium-Nickel Stainless Steel", Corros. Sci., vol. 6(1966): p. 421-433.

50. K. Osozawa and H. J. Engell,"The Anodic Polarization Curves of Iron-Nickel-Chromium Alloys", Corros. Sci., vol. 6(1966): p. 389-393.

51. H. Kaesche, Metallic Corrosion, National Associate of Corrosion Engineers, 1985),

52. M. S. Basiouny and S. Haruyama,"The Polarization Behavior of Fe-Cr Alloys in Acidic Sulphate Solutions in the Active Region", Corros. Sci., vol. 16(1976): p. 529-540.

53. M. A. Gaudett and J. R. Scully,"Distributions of Cr Depletion levels in Sensitized AISI 304 Stainless Steel and Its Implications Concerning Intergranular Corrosion Phenomena", Journal of the Electrochemical Society, vol. 140,No. 12 (1993): p. 3425-3425.

54. K. Aoki,"Theory of ultramicroelectrodes", Electroanalysis, vol. 5(1993): p. 627-639.

55. M. E. Goldman, Amorphous metallic coatings with tunable corrosion properties based on Al-Co-Ce(Mo) alloy compositions, Corrosion/2004, paper 04276, (New Orleans, LA, NACE International, 2004).

56. J. C. Rushing and M. Edwards,"Effect of aluminium solids and chlorine on cold water pitting of copper", Corros. Sci., vol. 46(2004): p. 3069-3088.

57. B. Marshall, "Initiation, propagation, and mitigation of aluminum and chlorine induced pitting corrosion" Master thesis at Virginia Tech, (2004), 29.

58. M. Romanoff, Underground Corrosion, (Washington D.C.: National Bureau of Standards, 1957),

59. M. F. Hurley and J. R. Scully, Corrosion Resistant Reinforcement for Concrete Structures: Corrosion Propagation Behavior, Corrosion2006, 06340, (San Diego, NACE, 2006).

60. B. A. Kehler, G. O. Ilevbare and J. R. Scully,"Crevice Corrosion Stabilization and Repassivation Behavior of Alloy 625 and Alloy 22", Corrosion, vol. 58,No. 12 (2001): p. 1042-1065.

61. J. R. Kearns, Crevice, R. Baboian, (Ed.), Corrosion Tests and Standards: Application and Interpretation, ASTM, 1995),

62. F. Gui and R. G. Kelly, Characterization of Wicking and Wetting Ability of Corrosion Prevention Compounds, ECS Meeting, PV 2004-14, 421,431, (Honolulu, HI, USA, The Electrochemical Society', 2004).

63. C. S. Wichman and J. R. Scully, Determining a Suitable Environment for the Investigation of Intergranular Corrosion Propagation by Interactions Between Sensitized Grain Boundaries. University of Virginia, Charlottesville, VA, 2003.

64. T. Shibata and T. Takeyama,"Stochastic Theory of Pitting", Corrosion, vol. 33,No. 7 (1977): p. 243251.

65. M. Pourbaix,"Some applications of potential-pH diagrams to the study of localized corrosion", J. Electrochem. Soc., vol. 132,No. 2 (1976): p. 25C-36C.

66. N. D. Budiansky, "M.S. Thesis-Origins of Persistent Interactions Among Localized Corrosion Sites Investigated Using Experimental Electrode Arrays" University of Virginia, (2003), 215.

67. J. A. L. Dobbelarr, E. C. M. Herman and J. H. W. De Wit,"The Corrosin Behavior of Iron Chromium Alloys in 0.05 M Sulphuric Acid", Corros. Sci., vol. 33,No. 5 (1992): p. 765-778.

68. M. Keddam, O. R. Mattos and H. Takenouti,"Mechansims of Anodic Dissolution of Iron-Chromium Alloys Investigated By Electrode Impedences-I. Experimental Results and Reaction Model", Electrochmica Acta., vol. 31,No. 9 (1986): p. 1147-1158. 

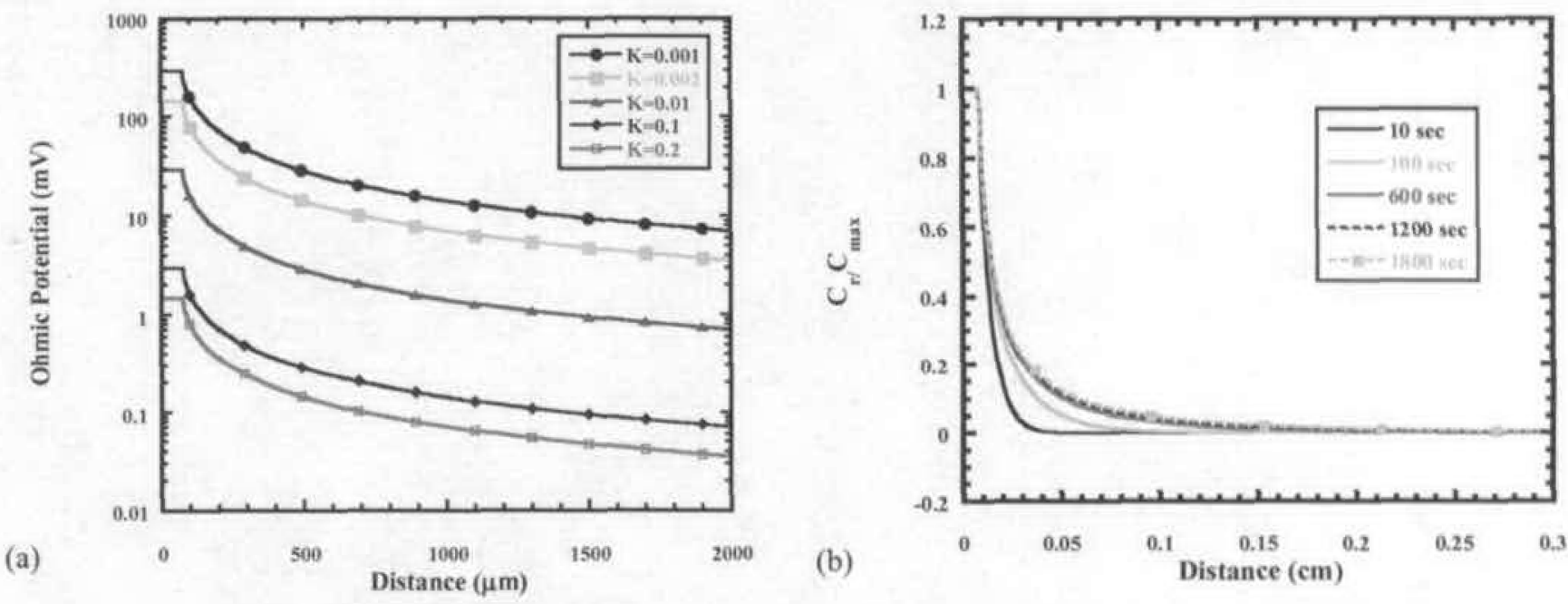

Figure 1. a) Ohmic potential field distribution in solution just above an electrode surface for a flush mounted circular electrode of $150 \mathrm{um}$ with $0.1 \mathrm{~A} / \mathrm{cm}^{2}$ current density using Newman's solution. Solution conductivity (K) are in units of $\Omega^{-1}-\mathrm{cm}^{-1}$. b) $\mathbf{H}^{+}$ion concentration field calculated using Carslaw and Yaeger equations. ${ }^{30}$

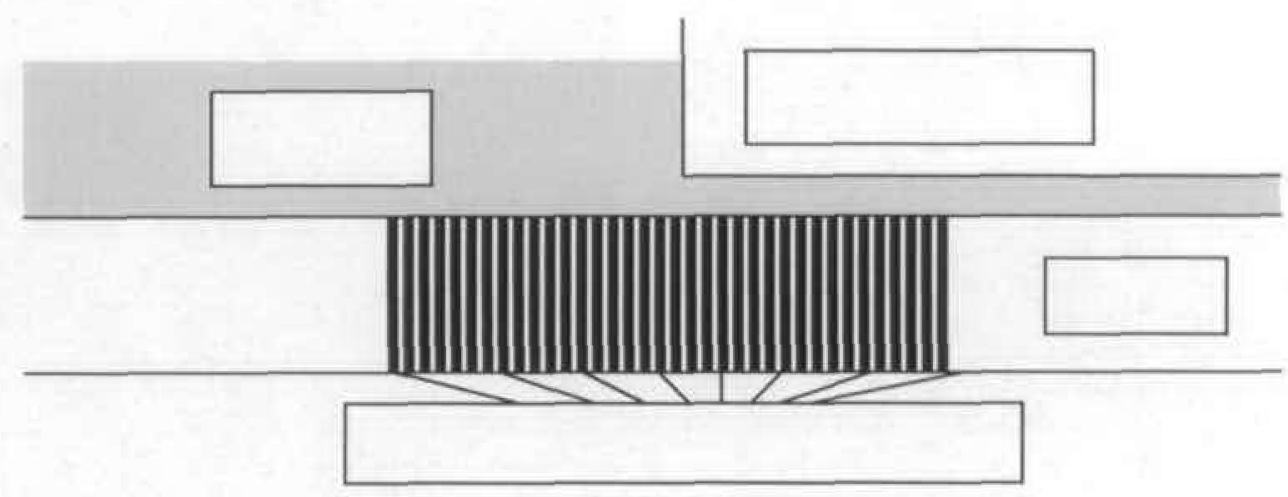

Figure 2. A schematic diagram of the cross section of a multi-electrode array in conjunction with a crevice former. The crevice former can be placed anywhere along the MEA allowing different regions, of the MEA, to be exposed to the bulk solution with the remainder to be located within the crevice area. 


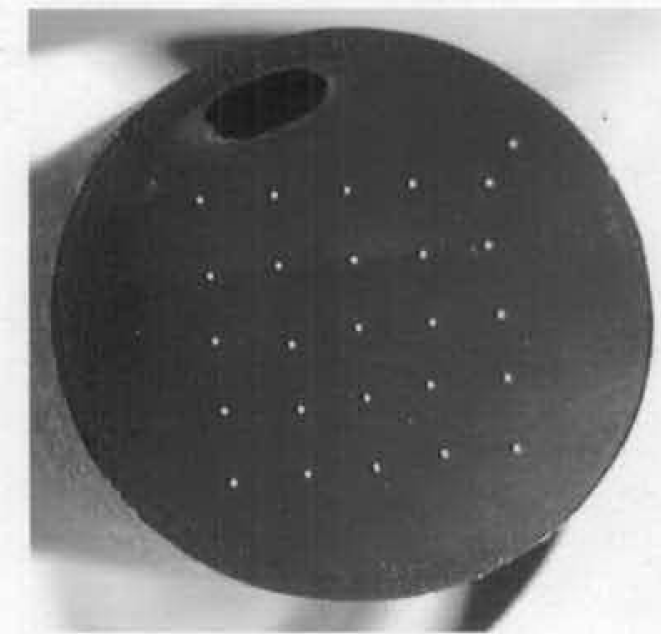

(a)

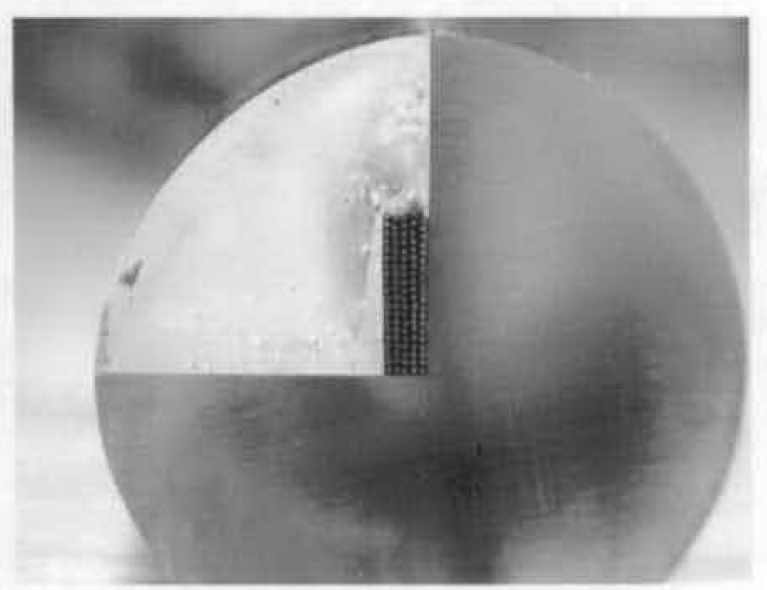

(b)

Figure 3. Arrangement of a multi-electrode array in a (a) $5 \times 5$ far spaced configuration and (b) close spaced $5 \times 20$ configuration.
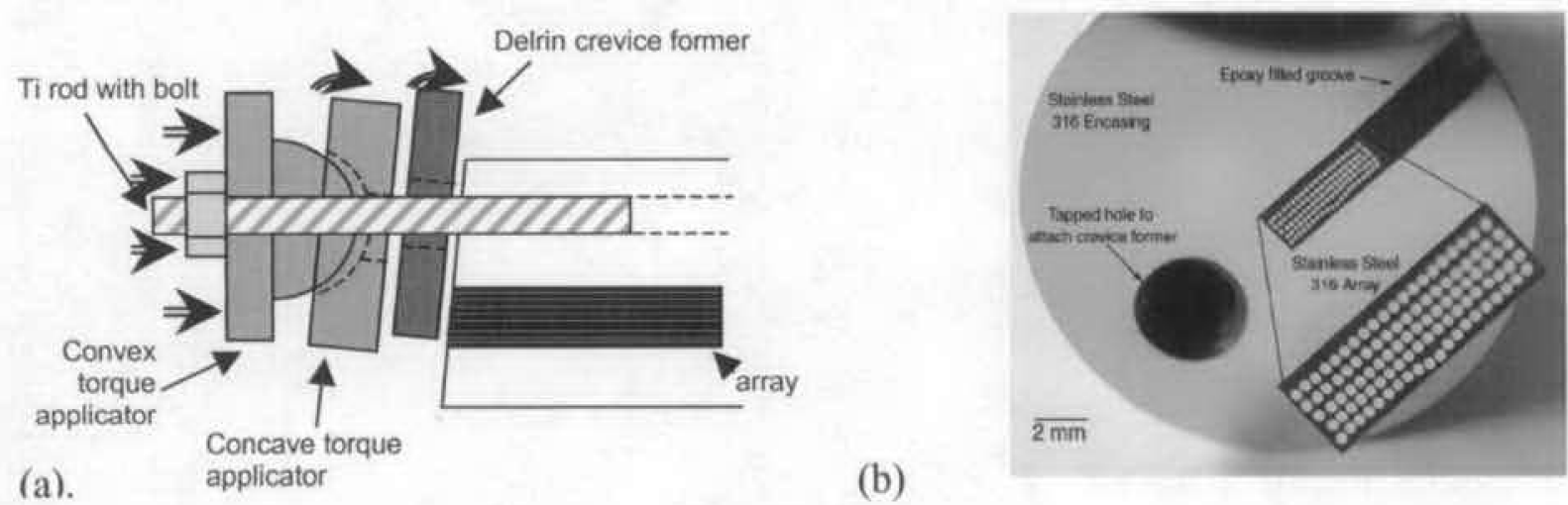

(b)

Figure 4. a) Cross section schematic of the crevice former setup showing the ball and socket joint to ensure a flush crevice former on the surface of the MEA and b) Planar view of the MEA used in crevice corrosion experiments. As shown, the solid metal encasing was grooved to allow the MEA to be mounted in the center of the encasing. Additionally, the threaded hole for crevice former attachment is shown. 


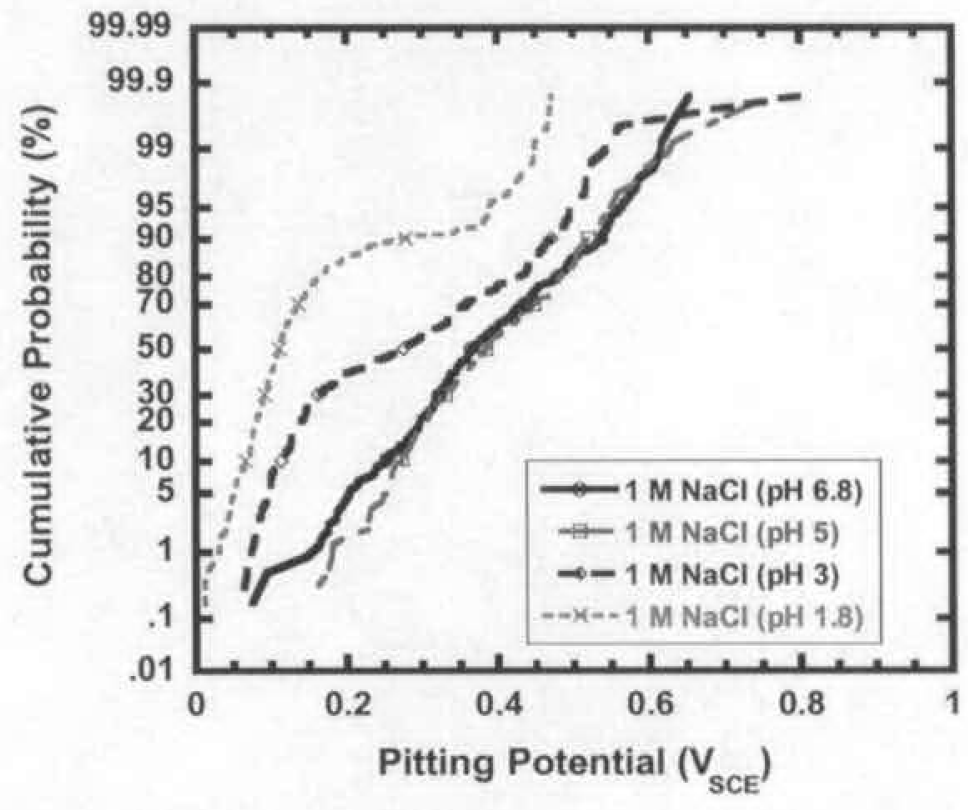

Figure 5. The cumulative probability of pitting potential for AISI $316 \mathrm{SS}$ in $1 \mathrm{M} \mathrm{NaCl} 47^{\circ} \mathrm{C}$ at different pHs.

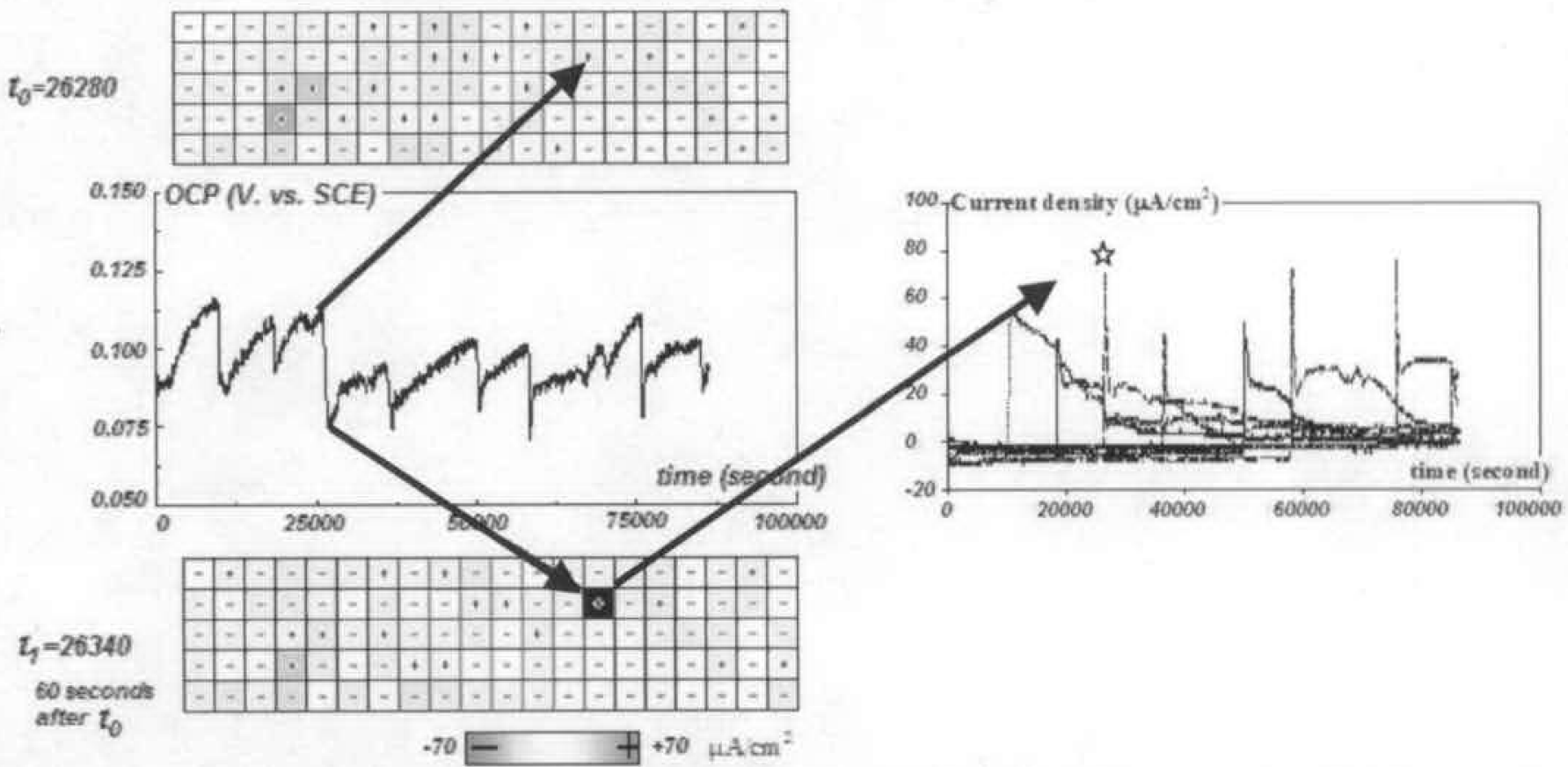

Figure 6. OCP vs. time for Cu MEA after a second $5 \mathrm{ppm}$ free chlorine was added in the synthetic drinking water. Stationary current maps are shown immediately before and immediately after free chlorine addition. Immediately following free chlorine addition, one electrode begins pitting actively, as shown by the dark color with a plus sign, indicating high anodic dissolution rates. Eight current peaks for different wires in the right figure correspond to the eight potential drops in the left figure at different times. 


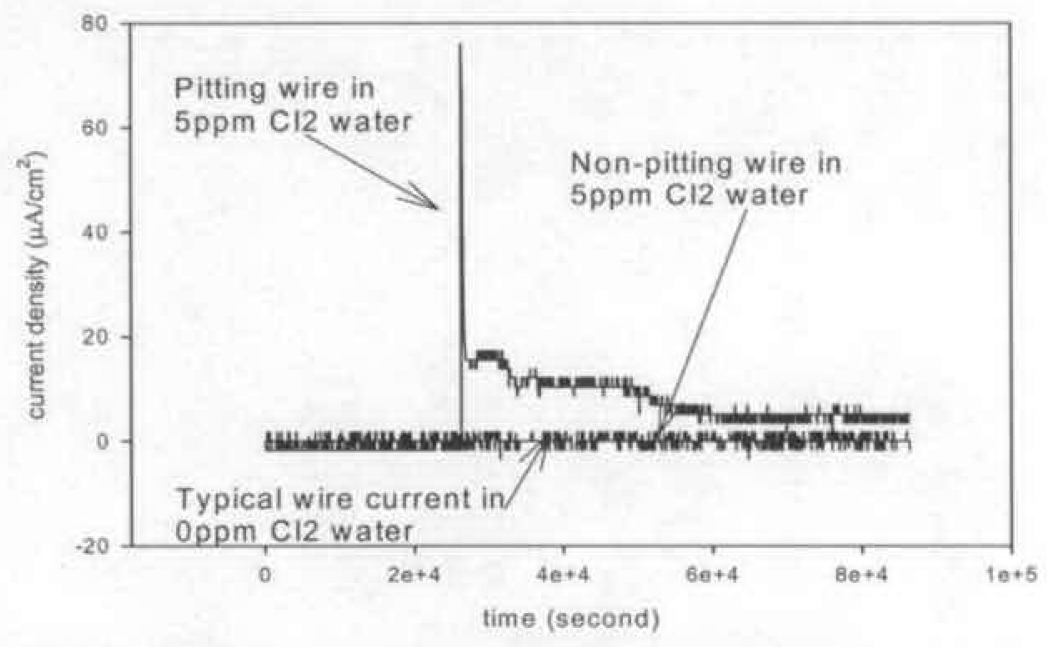

Figure 7. Current density vs, time plot for the wire corresponding to the dark black square in Figure 5. As shown, this wire became a persistent anode following free chlorine addition. Typical current density of copper wire in $0 \mathrm{ppm}$ chlorine water is also shown for comparison, which is indistinguishable from the non pitted wire in $5 \mathrm{ppm}$ chlorine water. 

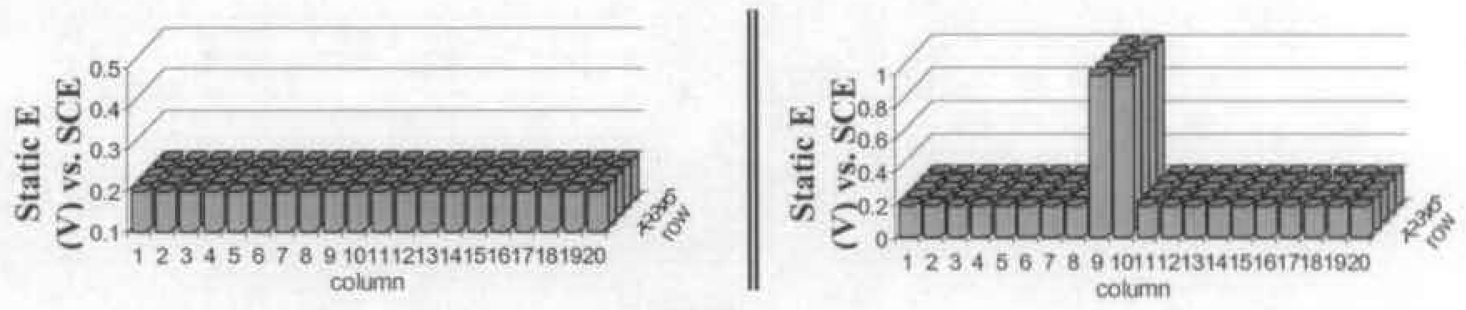

Time

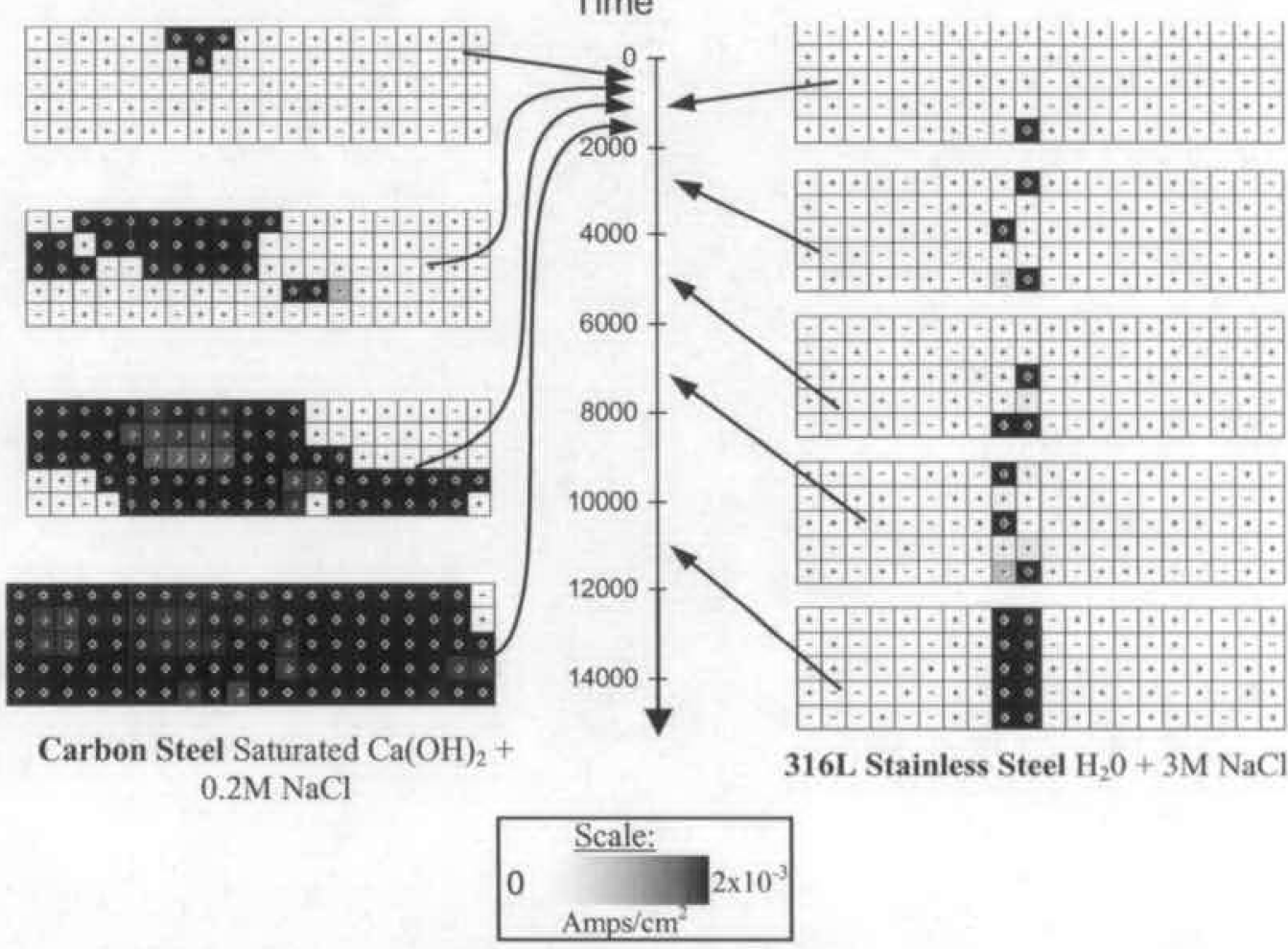

Figure 8. The spreading of depassivated surfaces on carbon steel and 316L stainless steel under potentiostatic control. In the left column are results from testing conducted on carbon steel, all electrodes held at $0.2 \mathrm{~V}$ vs. $\mathrm{SCE}$, in saturated $\mathrm{Ca}(\mathrm{OH})_{2}+0.2 \mathrm{M} \mathrm{NaCl}$. In the right column are results from testing conducted on $316 \mathrm{~L}$ in a considerably more aggressive electrolyte $\mathrm{CH}_{2} \mathrm{O}+3 \mathrm{M}$ $\mathrm{NaCl}$ ) with the 2 middle rows of electrodes held at an elevated potential. A shaded box in the grid represents $i_{\text {wire }}>2 \times 10^{-3} \mathrm{Amps} / \mathrm{cm}^{2}$. 


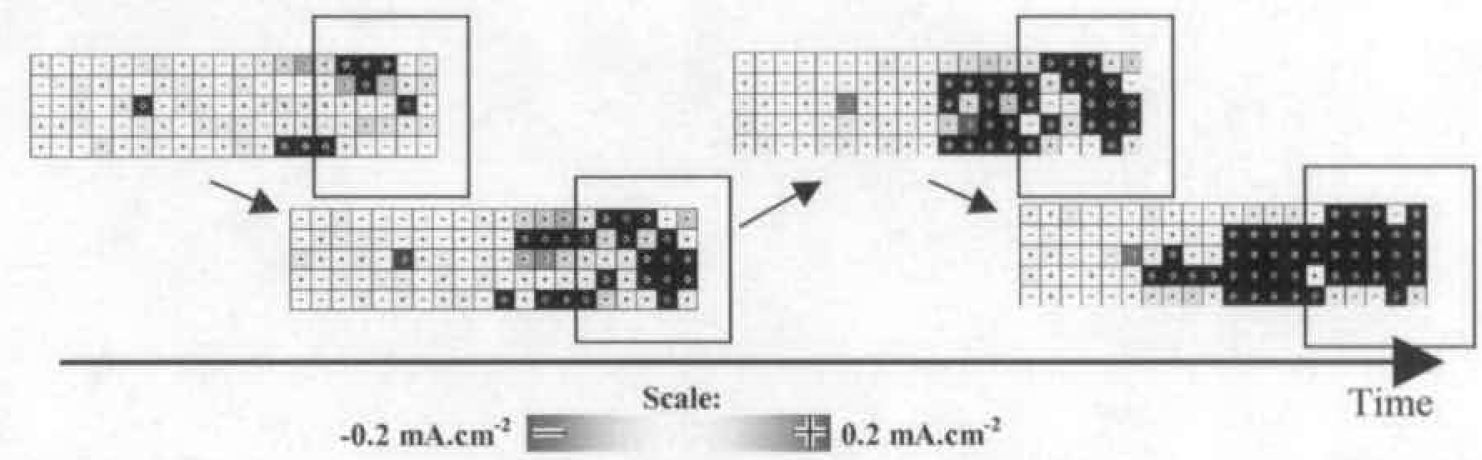

Figure 9. Stainless Steel 316 wires in aerated $0.6 \mathrm{M} \mathrm{NaCl}$ neutral solution at $50^{\circ} \mathrm{C}$. Propagation of crevice corrosion under a crevice as well as pitting corrosion outside the crevice is observed at $100 \mathrm{mV}$ SCE.

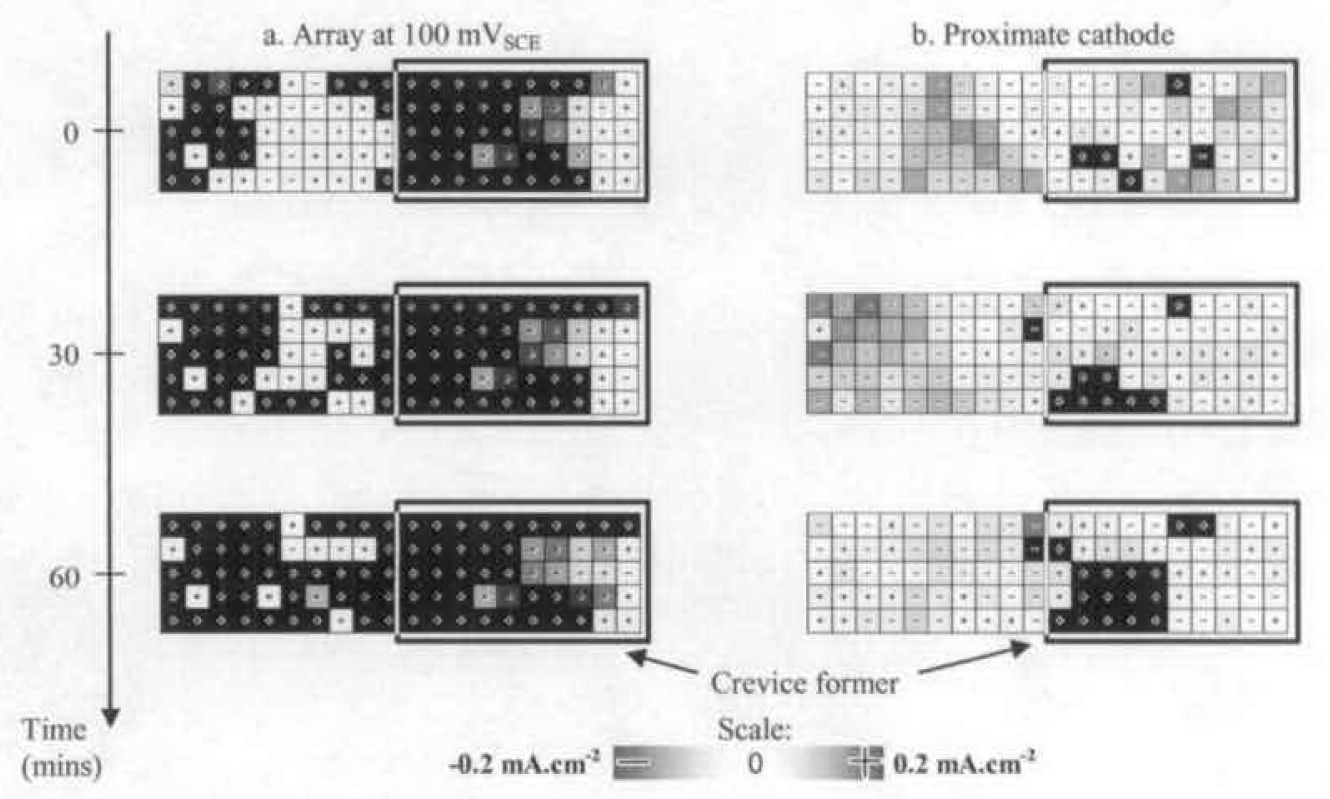

Figure 10. Evolution of the current with time on an array partly covered with a crevice former (not to scale). Stainless Steel 316 wires in aerated $1 \mathrm{M} \mathrm{NaCl}$ neutral solution at $47^{\circ} \mathrm{C}$. Every square represents one electrode, scales are shown for both series: a. anodically polarized array at $100 \mathrm{mV}_{\mathrm{SCE}}$ b. proximate cathode with anodic crevice, outside wires at $-400 \mathrm{mV} \mathrm{SCE}_{\mathrm{S}}$ and inside wires at $100 \mathrm{mV}$ SCE. 


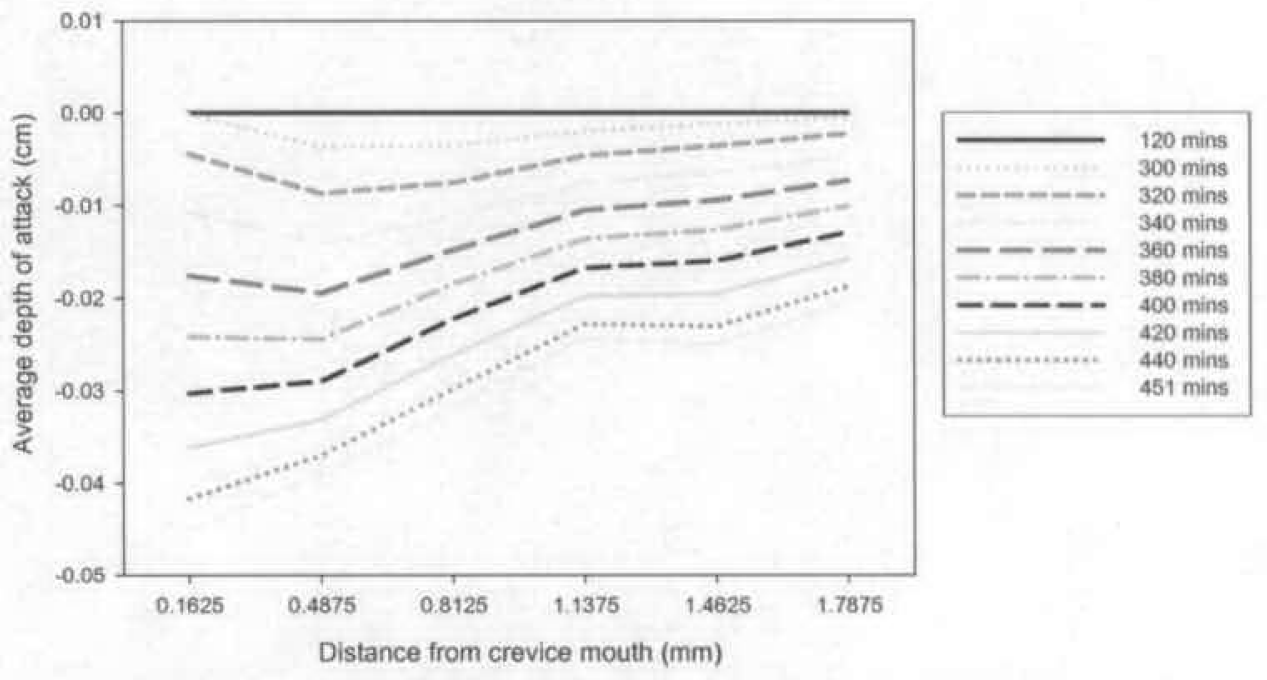

Figure 11. Calculated average attack depth profile under crevice former from measured net charge at different times at $100 \mathrm{mV}_{\mathrm{SCE}}$ after 3 days at $\mathrm{OCP}, 1$ day at $0 \mathrm{mV}_{\mathrm{SCE}}$ and 1 day at $50 \mathrm{mV}_{\mathrm{SCE}}$ in aerated $0.6 \mathrm{M} \mathrm{NaCl}$ at $50^{\circ} \mathrm{C}$. Array mounted in polymer encasing with 85 inch.pounds torque applied on the crevice former.

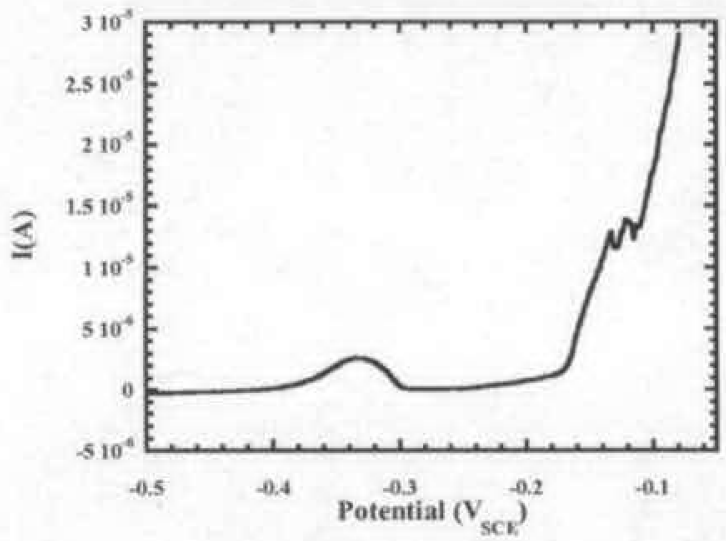

(b)

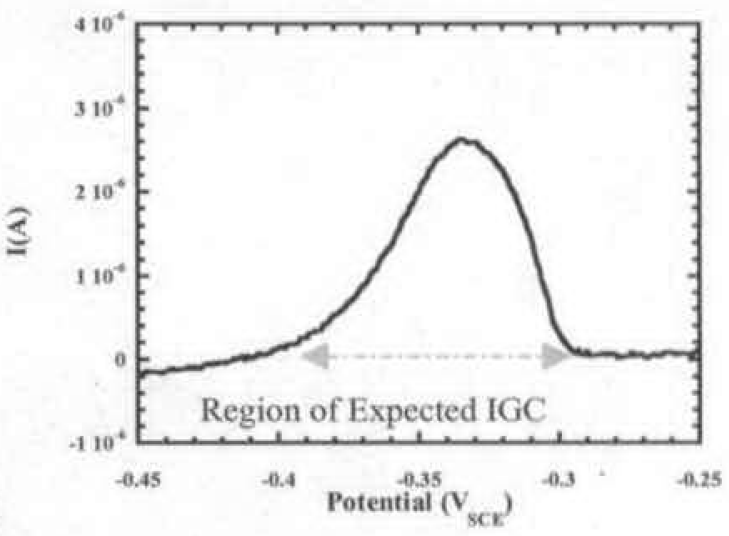

Figure 12. (a) The polarization curve of sensitized $304 \mathrm{SS}$ in $0.06 \mathrm{M} \mathrm{HCl}+0.01 \mathrm{M} \mathrm{KSCN}$ at $60^{\circ} \mathrm{C}$. (b) The active/passive behavior region of the E-I curve indicating the region of expected IGC. 


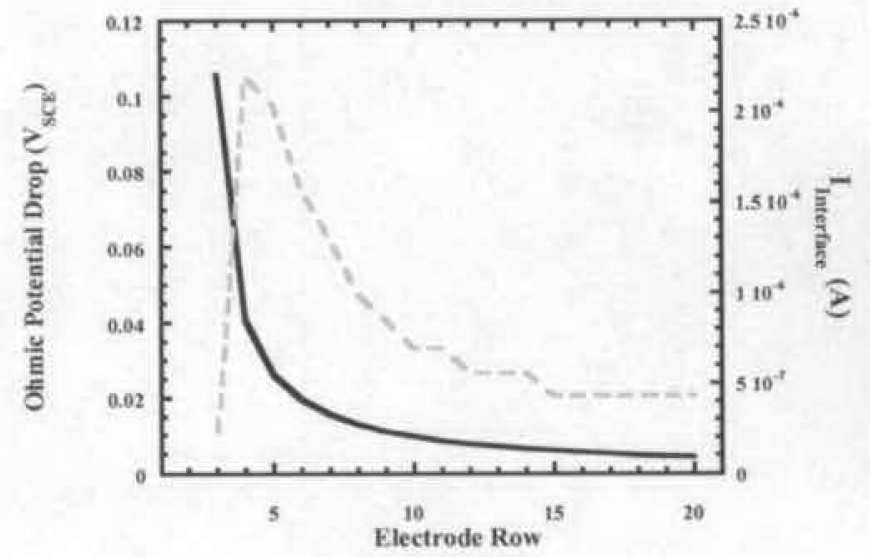

Figure 13. Calculated ohmic potential drop caused by actively pitted electrodes and the resulting $V_{\text {ohmic }}$ and $I_{\text {Interface }}$ as a function of electrode rows. Intergranular attack is expected to reach a peak between rows 3 and 11 as seen in Figure 14.

(a)

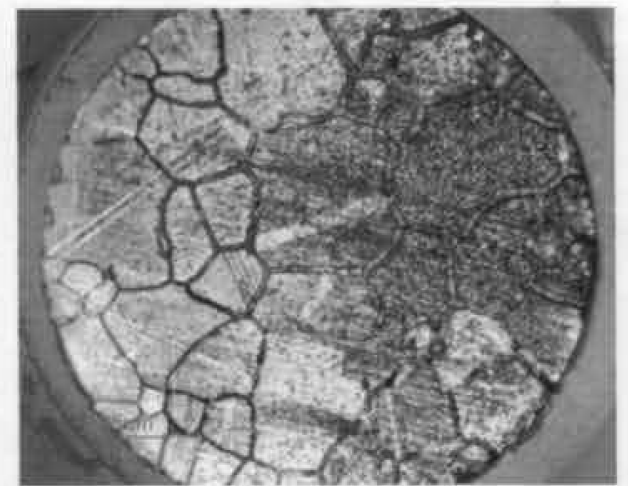

(c)

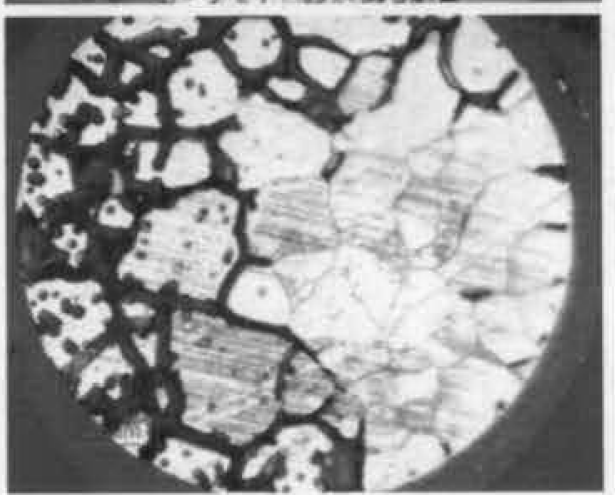

Intergranular corrosion zone

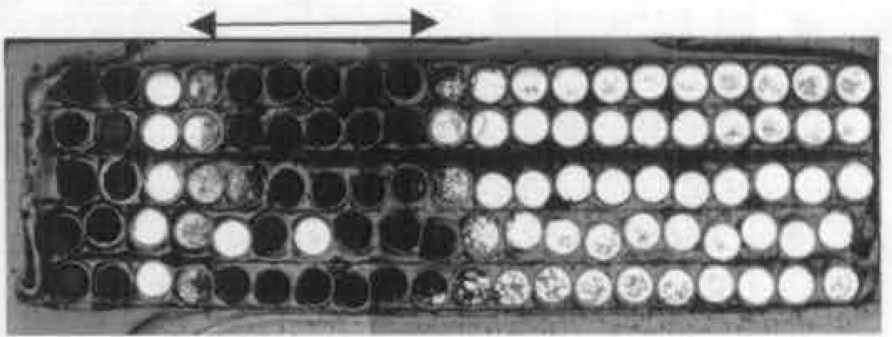

Figure 14. Optical micrograph of the MEA surface after $(1200$ sec) initiated IGC interaction experiments in $0.06 \mathrm{M} \mathrm{HCl}+0.01$ $\mathrm{M} \mathrm{KSCN}$ at $60^{\circ} \mathrm{C}$. The two rows at far left were pitted while intergranular corrosion occurs at right.

(b)

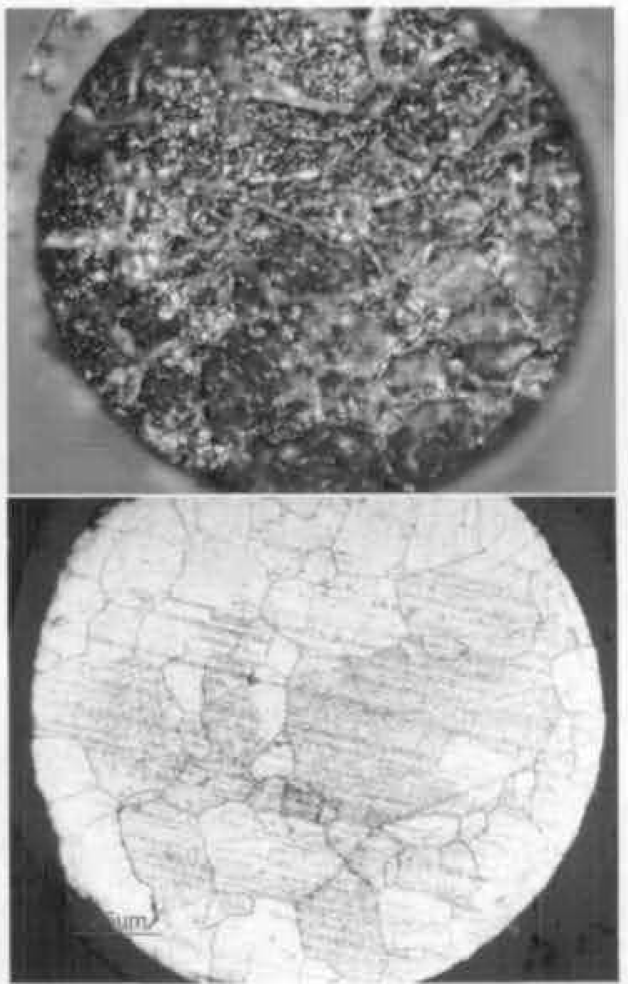

(d)

Figure 15. Photomicrographs of individual sensitized 304 stainless steel electrodes from (a) row 3, (b) row 6, (c) row 11, (d) row 19 after induced interaction experiments for sensitized 304 SS in $0.06 \mathrm{M} \mathrm{HCl}+0.01 \mathrm{M} \mathrm{KSCN}(\mathrm{pH} \mathrm{1.22})$ at $60^{\circ} \mathrm{C}$. Micrographs indicate the level of damage from induced interactions experiments after 20 minutes. 


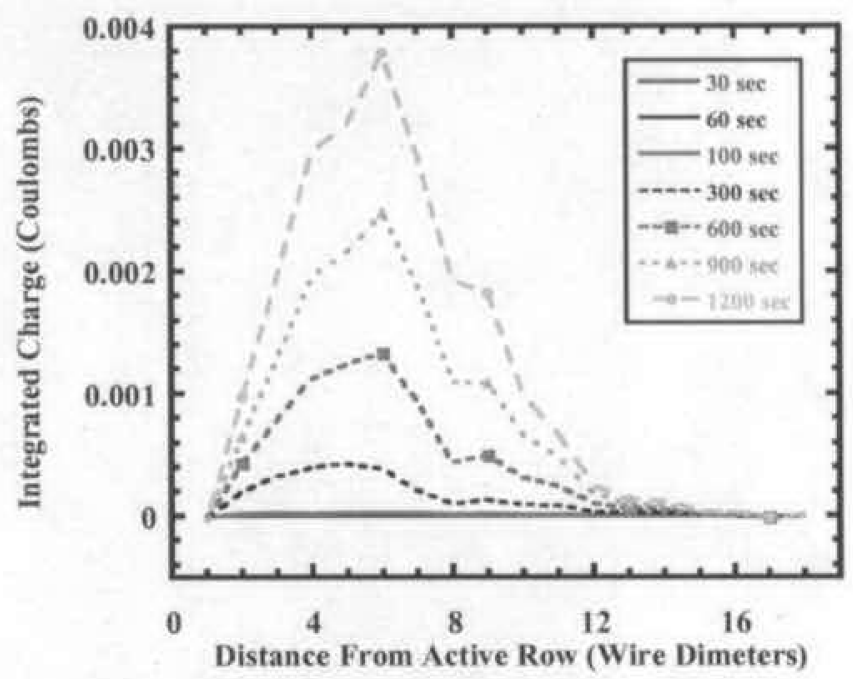

Figure 16. Integrated charge as a function of distance and time for sensitized stainless steel electrodes exposed to induced interactions experiments. The amount of integrated charge is directly related to the amount of IGC damage of electrodes. The shape of the damage zone closely matches the shape of the polarization curve due to ohmic potential drop and solution enhancement regions.

(a)

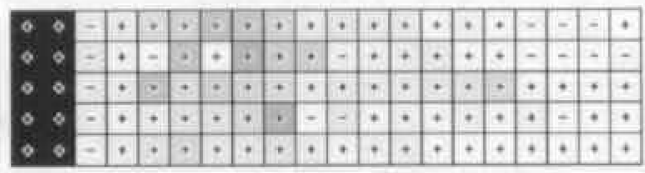

(c)

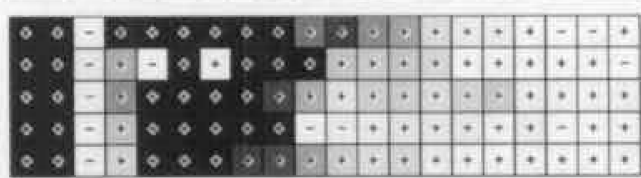

(e)

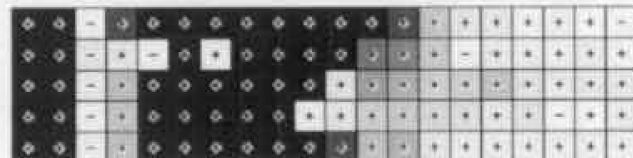

(b)

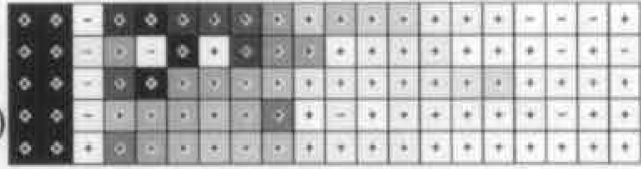

(d)

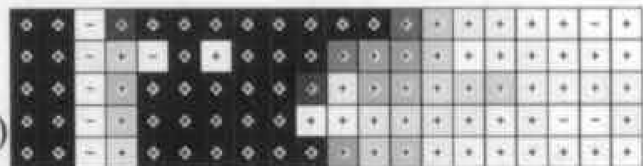

(f)

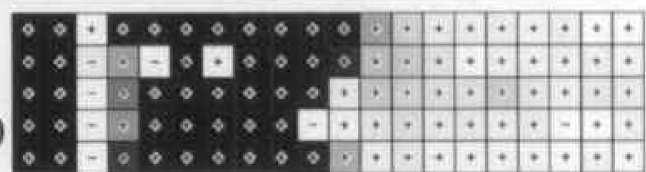

Current Deasity $\left(\mathrm{A}_{\mathrm{cm}}{ }^{2}\right)$

Anodic $7.4 \times 10^{-3}$

Cathodic

$-7.4 \times 10^{-3}$

Figure 17. Current map of $5 \times 20$ sensitized $304 \mathrm{SS} \mathrm{MEA} \mathrm{in} 0.06 \mathrm{M} \mathrm{HCl}+0.01 \mathrm{M} \mathrm{KSCN}$ at $60^{\circ} \mathrm{C}$ acquired at given times: (a) 60 seconds, (b) 120 seconds, (c) 300 seconds, (d) 600 seconds, (e) 900 seconds, and (f) 1200 seconds. Note: Two electrodes located in rows 5 and 7 do not show any electrical signal most likely due to loss of electrical contact. The data obtained from these electrodes were not included in any data analysis. 